Original Research Paper

\title{
Geometrical Synthesis of the Distribution Mechanisms
}

\author{
Florian Ion T. Petrescu \\ Department of Theory of Mechanisms and Robots, Bucharest Polytechnic University, Bucharest, Romania
}

Article history

Received: $12-2-2015$

Revised: 05-3-2015

Accepted: 07-3-2015

\begin{abstract}
In this study the author presents shortly some few original trigonometric methods to make the synthesis of some main distribution mechanisms. One presents four main modules of distribution mechanisms, with rotary cam and translated or rotated tappet plane or with roll, used with priority at the distribution mechanisms from the heat engines with internal combustion. These types of distribution mechanisms can improve the changes of gases and may decrease significantly the level of vibration, noises and emissions. As long as we produce electricity and heat by burning fossil fuels is pointless to try to replace all thermal engines with electric motors, as loss of energy and pollution will be even larger. However, it is well to continuously improve the thermal engines, to reduce thus fuel consumption. At the heat engine with internal combustion a great loss of power is realized and by the distribution mechanism, reason for that we must try to improve the functionality of this mechanism. The synthesis of these types of distribution mechanisms can be made shortly by the Cartesian coordinates, but to determine these coordinates we need and some trigonometric parameters of the mechanisms.
\end{abstract}

Keywords: Mechanisms with Cam, Distribution Mechanism, Rotary Cam, Balanced Roller Tappet, Cam Kinematic, Cam Synthesis, Dynamic Synthesis, Cam efficiency

\section{Introduction}

Distribution mechanisms with rotary cam and translational movement or rotating tappet plane or with roller have all a unique kinematic due primarily of the any mechanism geometry, which forces us to study them in greater detail if we need to determine the kinematic and dynamic precision of these mechanisms (Amoresano et al., 2013; Anderson, 1984; Angelas and Lopez-Cajun, 1988; Antonescu et al., 2000; Antonescu et al., 1987; Barzegari, 2011; Bishop, 1950; Choi and Kim, 1994; De Falco et al., 2013a; 2013b; Ganapathi and Robinson, 2013; Giordana et al., 1979; Hain, 1971; Heywood, 1988; Hrones, 1948; Karikalan et al., 2013; Leidel, 1997; Mahalingam and Ramesh Bapu, 2013; Naima and Liazid, 2013; Narasiman et al., 2013; Petrescu and Petrescu, 1995; 2005a; 2005b; Petrescu et al., 2005; Petrescu, 2008; Petrescu and Petrescu, 2014; 2013a; 2013b; 2011; Petrescu, 2012a; 2012b; Petrescu and Petrescu, 2013c; 2013d; Rahmani et al., 2013; Ravi and Subramanian, 2013; Ronney et al., 1994; Samim and Tümer, 1993;
Sapate and Tikekar, 2013; Sethusundaram et al., 2013; Shriram, 2012; Taraza, 2002; Wang, 2011; Xianying, 2011; Zahari et al., 2013; Zhao et al., 2012).

Internal combustion engines in four-stroke (Otto, Diesel) are robust, dynamic, compact, powerful, reliable, economic, autonomous, independent and will be increasingly clean.

In full energy crisis since 1970 until today, production and sale of cars equipped with internal combustion heat engines has skyrocketed, from some millions yearly to over sixty millions yearly now and the world fleet started from tens of millions reached today the billion.

At the heat engine with internal combustion a great loss of power is realized and by the distribution mechanism, reason for that we must try to improve the functionality of this mechanism (Amoresano et al., 2013; Anderson, 1984; Angelas and Lopez-Cajun, 1988; Antonescu et al., 2000; Antonescu et al., 1987; Barzegari, 2011; Bishop, 1950; Choi and Kim, 1994; De Falco et al., 2013a; 2013b; Ganapathi and Robinson, 2013; Giordana et al., 1979; Hain, 1971; Heywood, 
1988; Hrones, 1948; Karikalan et al., 2013; Leidel, 1997; Mahalingam and Ramesh Bapu, 2013; Naima and Liazid, 2013; Narasiman et al., 2013; Petrescu and Petrescu, 1995; 2005a; 2005b; Petrescu et al., 2005; Petrescu, 2008; Petrescu and Petrescu, 2014; 2013a; 2013b; 2011; Petrescu, 2012a; 2012b; Petrescu and Petrescu, 2013c; 2013d; Rahmani et al., 2013; Ravi and Subramanian, 2013; Ronney et al., 1994; Samim and Tümer, 1993; Sapate and Tikekar, 2013; Sethusundaram et al., 2013; Shriram, 2012; Taraza, 2002; Wang, 2011; Xianying, 2011; Zahari et al., 2013; Zhao et al., 2012).

These types of distribution mechanisms can improve the changes of gases and may decrease significantly the level of vibration, noises and emissions, if designed properly.

As long as we produce electricity and heat by burning fossil fuels is pointless to try to replace all thermal engines with electric motors, as loss of energy and pollution will be even larger. However, it is well to continuously improve the thermal engines, to reduce thus fuel consumption.

The synthesis of these types of distribution mechanisms can be made shortly by the Cartesian coordinates, but to determine these coordinates we need and some trigonometric parameters of the mechanisms.

\section{Synthesis of the Distribution Mechanism Module C}

In the Fig. 1 it presents the kinematics schema of the classic distribution mechanism, in two consecutive positions; with a interrupted line is represented the particular position when the follower is situated in the most down plane, $(\mathrm{s}=0)$ and the cam which has an orally rotation, with constant angular velocity, $\omega$, is situated in the point $\mathrm{A}^{0}$, (the recordation point between the base profile and the up profile, particular point that mark the up begin of the follower, imposed by the cam-profile); with a continue line (green) is represented the superior couple in someone position of the up phase.

From initial position $\left(\mathrm{x}_{\mathrm{F}}\right)$ to a someone position $\left(\mathrm{x}_{\mathrm{M}}\right)$ the cam (camshaft) was rotated with an $\varphi$ angle. In this time the position vector $r=r_{A}$ was rotated (in relation to the mobile axis $\mathrm{x}_{\mathrm{M}}$ ) with the $\theta$ angle, which is a sum between $\varphi$ and $\tau$ (where $\tau$ is the transmission angle who occurs between the initial, vertical, fix axis and the position vector $r=r_{A}$. The cam or camshaft movement is given by $\theta$ angle and the position vector $r$ movement is characterized by the $\theta$ angle (this is all the main problem of the classical distribution mechanism). Any A position point (the contact point between cam and tappet) is given by the coordinates $r$ and $\theta$ (polar) or $x_{A}$,
$\mathrm{y}_{\mathrm{A}}$ (Cartesian), for tappet in a fix system and for the cam in a mobile system.

The point $\mathrm{A}^{0}$, which marks the initial couple position, represents in the same time the contact point between the cam and follower in the first position. The cam has an angular velocity $\omega$ (the camshaft angular velocity).

Cam is rotating with the velocity $\omega$ describing the angle $\varphi$, which show how the base circle has rotated in the orally sense, (with the camshaft together); this rotation can be seen on the base circle between the two particular points, $\mathrm{A}^{0}$ and $\mathrm{A}^{0 \mathrm{i}}$.

In this time the vector $\mathrm{r}_{\mathrm{A}}=\mathrm{OA}$ (which represents the distance between the centre of cam $\mathrm{O}$ and the contact point $\mathrm{A}$ ), has rotating (trigonometric) with the $\tau$ angle. If one measures the $\theta$ angle, which positions the general vector $\mathrm{r}_{\mathrm{A}}$ in function of the particular vector, $\mathrm{r}_{\mathrm{A} 0}$, it obtains the base relation noted with $(0)$ :

$\theta=\varphi+\tau$

where, $r_{\mathrm{A}}$ is the module of the vector $\vec{r}_{A}$ and $\theta_{\mathrm{A}}$ represents the phase angle of the vector $\vec{r}_{A}$.

The rotating velocity of the vector $\vec{r}_{A}$ is $\dot{\theta}_{A}$ which it's a function of the angular velocity of the camshaft, $\omega$ and a rotating $\varphi$ angle, (by the movement laws $s(\varphi)$, $\left.\mathrm{s}^{\prime}(\varphi), \mathrm{s}^{\prime}(\varphi)\right)$.

The follower isn't acted directly by the cam, by the angle, $\varphi$ and by the angular velocity $\omega$; it's acted by the vector $\vec{r}_{A}$, which has the module $r_{A}$, the position angle $\theta_{A}$ and the angular velocity $\dot{\theta}_{A}$. From here result a particular (dynamic) kinematics, the classical kinematics being just a static and approximate kinematics.

Kinematics one defines the next velocities (Fig. 1).

$\vec{v}_{1}=$ The cam velocity; which is the velocity of the vector $\vec{r}_{A}$, in the point A (that is not a fix point on the cam, but it is a point which is moving on the cam); now the classical relation (1) become an approximately relation and the real relation takes the form (2):

$v_{1}=r_{A} \cdot \omega$

$v_{1}=r_{A} \cdot \dot{\theta}_{A}$

The velocity $\vec{v}_{1}=A C$ is separating in the velocity $\vec{v}_{2}$ $=\mathrm{BC}$ (the follower velocity which act in its axe, on a vertical direction) and $\vec{v}_{12}=\mathrm{AB}$ (the slide velocity between the two profiles, the sliding velocity between the cam and the follower, which works by the direction of the commune tangent line of the two profiles in the contact point). 


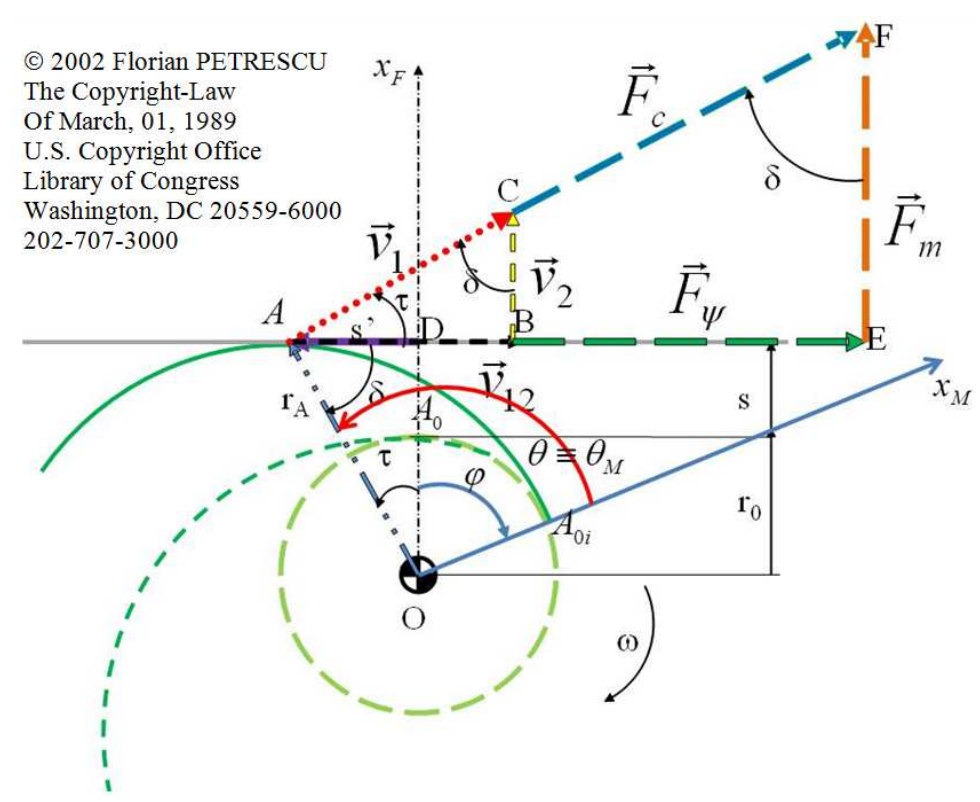

Fig. 1. Mechanism with rotating cam and plane translating tappet

Usually the cam profile is synthesis with the $\mathrm{AD}=$ s' known, for the classical module $\mathrm{C}$ and one can write the relations $(3-7)$ :

$r_{A}^{2}=\left(r_{0}+s\right)^{2}+s^{\prime 2}$

$r_{A}=\sqrt{\left(r_{0}+s\right)^{2}+s^{\prime 2}}$

$\cos \tau=\frac{r_{0}+s}{r_{A}}=\frac{r_{0}+s}{\sqrt{\left(r_{0}+s\right)^{2}+s^{\prime 2}}}$

$\sin \tau=\frac{A D}{r_{A}}=\frac{s^{\prime}}{r_{A}}=\frac{s^{\prime}}{\sqrt{\left(r_{0}+s\right)^{2}+s^{\prime 2}}}$

$v_{2}=v_{1} \cdot \sin \tau=r_{A} \cdot \dot{\theta}_{A} \cdot \frac{s^{\prime}}{r_{A}}=s^{\prime} \cdot \dot{\theta}_{A}$

Now, the follower velocity isn't $\dot{s}\left(v_{2} \neq \dot{s} \equiv s^{\prime} \cdot \omega\right)$, but it's given by the relation (9). At the classical distribution mechanism the transmitting function $\mathrm{D}$, is given by the relations (8):

$$
\begin{aligned}
& \left\{\begin{array}{l}
\dot{\theta}_{A}=D \cdot \omega \\
D=\frac{\dot{\theta}_{A}}{\omega}=\frac{v_{2}}{\dot{s}}
\end{array}\right. \\
& v_{2}=s^{\prime} \cdot \dot{\theta}_{A}=s^{\prime} \cdot D \cdot \omega=\dot{s} \cdot D
\end{aligned}
$$

Determination of the sliding velocity between the two profiles in contact is made by the relation (10):

$\left\{\begin{array}{l}v_{12}=v_{1} \cdot \cos \tau= \\ =r_{A} \cdot \dot{\theta}_{A} \cdot \frac{r_{0}+s}{r_{A}}=\left(r_{0}+s\right) \cdot \dot{\theta}_{A}\end{array}\right.$

The angles $\tau$ (and then $\theta_{A}$ ) will be determined with its first and second derivatives.

The $\tau$ angle has been determined from the triangle ODA (Fig. 1) with the relations (11-13):

$$
\begin{aligned}
& \sin \tau=\frac{s^{\prime}}{\sqrt{\left(r_{0}+s\right)^{2}+s^{\prime 2}}} \\
& \cos \tau=\frac{r_{0}+s}{\sqrt{\left(r_{0}+s\right)^{2}+s^{\prime 2}}} \\
& \operatorname{tg} \tau=\frac{s^{\prime}}{r_{0}+s}
\end{aligned}
$$

One derives relation (11) in function of $\varphi$ angle and it obtains the expression (14):

$\tau^{\prime} \cdot \cos \tau=\frac{s^{\prime \prime} \cdot r_{A}-s^{\prime} \cdot \frac{\left(r_{0}+s\right) \cdot s^{\prime}+s^{\prime} \cdot s^{\prime \prime}}{r_{A}}}{\left(r_{0}+s\right)^{2}+s^{\prime 2}}$

The relation (14) will be written in the form (15): 


$$
\left\{\begin{array}{l}
\tau^{\prime} \cdot \cos \tau= \\
=\frac{s^{\prime \prime} \cdot\left(r_{0}+s\right)^{2}+s^{\prime \prime} \cdot s^{\prime 2}-s^{\prime 2} \cdot\left(r_{0}+s\right)-s^{\prime 2} \cdot s^{\prime \prime}}{\left[\left(r_{0}+s\right)^{2}+s^{\prime 2}\right] \cdot \sqrt{\left(r_{0}+s\right)^{2}+s^{\prime 2}}}
\end{array}\right.
$$

From the relation (12) one extracts the value of $\cos \tau$, which will be introduced in the left term of the expression (15); then one reduces $\mathrm{s}^{\prime} . \mathrm{s}^{, 2}$ from the right term of the expression (15) and it obtains the relation (16):

$$
\left\{\begin{array}{l}
\tau^{\prime} \cdot \frac{r_{0}+s}{\sqrt{\left(r_{0}+s\right)^{2}+s^{\prime 2}}} \\
=\frac{\left(r_{0}+s\right) \cdot\left[s^{\prime \prime} \cdot\left(r_{0}+s\right)-s^{\prime 2}\right]}{\left[\left(r_{0}+s\right)^{2}+s^{\prime 2}\right] \cdot \sqrt{\left(r_{0}+s\right)^{2}+s^{\prime 2}}}
\end{array}\right.
$$

After some simplifications one obtains finally the relation (17) which represents the expression of $\tau^{\prime}$ :

$$
\tau^{\prime}=\frac{s^{\prime \prime} \cdot\left(r_{0}+s\right)-s^{\prime 2}}{\left(r_{0}+s\right)^{2}+s^{\prime 2}}
$$

Now, when it was explicitly $\tau^{\prime}$, one can determine the next derivatives. The expression (17) will be derived directly and it can be obtained for begin the relation (18):

$$
\begin{aligned}
& \tau "= \\
& {\left[s^{\prime \prime \prime}\left(r_{0}+s\right)+s^{\prime \prime} s^{\prime}-2 s^{\prime} s^{\prime \prime}\right]\left[\left(r_{0}+s\right)^{2}\right.} \\
& \frac{\left.+s^{\prime 2}\right]-2\left[s^{\prime \prime}\left(r_{0}+s\right)-s^{\prime 2}\right]\left[\left(r_{0}+s\right) s^{\prime}+s^{\prime} s^{\prime \prime}\right]}{\left[\left(r_{0}+s\right)^{2}+s^{\prime 2}\right]^{2}}
\end{aligned}
$$

One reduces the terms from the first bracket of the numerator (s'.s"') and then one draws out s' from the fourth bracket of the numerator and one obtains the expression (19):

$$
\begin{aligned}
& \tau "= \\
& {\left[s^{\prime \prime \prime} \cdot\left(r_{0}+s\right)-s^{\prime} \cdot s^{\prime \prime}\right] \cdot\left[\left(r_{0}+s\right)^{2}+s^{\prime 2}\right]} \\
& \frac{-2 . s^{\prime} \cdot\left[s^{\prime \prime} \cdot\left(r_{0}+s\right)-s^{\prime 2}\right] \cdot\left[r_{0}+s+s^{\prime \prime}\right]}{\left[\left(r_{0}+s\right)^{2}+s^{\prime 2}\right]^{2}}
\end{aligned}
$$

Now, one can calculate $\theta_{\mathrm{A}}$, with its first two derivatives, $\dot{\theta}_{A}$ and $\ddot{\theta}_{A}$. We write $\theta$ and not $\theta_{\mathrm{A}}$, to simplify the notation. Now, one can determine (20), or relation $(0)$ :

$$
\theta=\tau+\phi
$$

One derives (20) and it obtains the relation (21): $\dot{\theta}=\dot{\tau}+\dot{\phi}=\tau^{\prime} \cdot \omega+\omega=\omega \cdot\left(1+\tau^{\prime}\right)=D \cdot \omega$

One makes the second derivative of (20) and the first derivative of (21) and it obtains (22):

$\ddot{\theta}=\ddot{\tau}+\ddot{\phi}=\tau^{\prime \prime} \cdot \omega^{2}=D^{\prime} \cdot \omega^{2}$

One can write now the transmitting functions, $D$ and $D^{\prime}$ (at the classical module C), in the forms (23-24):

$$
\begin{aligned}
& D=\tau^{\prime}+1 \\
& D^{\prime}=\tau^{\prime \prime}
\end{aligned}
$$

The follower velocity (relations from system 25), need the expression of the transmitted function, $D$ :

$v_{2}=s^{\prime} \cdot w=s^{\prime} \cdot \dot{\theta}_{A}=s^{\prime} \cdot \dot{\theta}=s^{\prime} \cdot D \cdot \omega=\dot{s} \cdot D$

Where:

$w=D \cdot \omega$

For the classical distribution mechanism (Module C), the variable $\mathrm{w}$ is the same with $\dot{\theta}_{A}$ (see the relation 25). But at the $\mathrm{B}$ and $\mathrm{F}$ modules (at the cam gears where the follower has roll), the transmitted function $D$ (and w), takes some complex forms.

Now, it can determine the acceleration of the follower (27):

$\ddot{y} \equiv a_{2}=\left(s^{\prime \prime} \cdot D+s^{\prime} \cdot D^{\prime}\right) \cdot \omega^{2}$

In the Fig. 2, it can be seen the kinematics classic and dynamic; the velocities (a) and the accelerations (b).

To determine the acceleration of the follower, are necessary s' and s', D and D', $\tau$ ' and $\tau$ '.

The kinematics dynamic diagrams of $v_{2}$ (obtained with relation 25 , Fig. $2 a$ ) and $a_{2}$ (obtained with relation 27, Fig. 2b), have more a dynamic aspect than a kinematic one. It has used the movement law SINE, a rotation velocity at the crankshaft, $\mathrm{n}=5500[\mathrm{rpm}]$, an up angle, $\varphi_{\mathrm{u}}=75$ [deg], a down angle $\varphi_{\mathrm{d}}=75$ [deg] (identically with the up angle), a ray at the basic circle of the cam, $\mathrm{r}_{0}=17[\mathrm{~mm}]$ and a maxim stroke of the follower, $\mathrm{h}_{\mathrm{T}}=6[\mathrm{~mm}]$.

Anyway, the dynamic is more complex, having in view the masses and the inertia moments, the resistant and motor forces, the elasticity constants and the amortization coefficient of the kinematics chain, the inertia forces of the system, the rotation velocity of the camshaft and the variation of the camshaft velocity, $\omega$ with the cam $\varphi$ position and with the rotation speed of the crankshaft, $n$. 


\section{Plotting (Synthesis) of Classical Cam Profile}

In xOy fixed system, Cartesian coordinates of point $\mathrm{A}$ of contact (of the tappet 2) are given by the position vector $\mathrm{r}_{\mathrm{A}}$ projections on the axes Ox Oy respectively and analytical expressions expressed by the relational system (28):

$$
\left\{\begin{array}{l}
x_{T}=r_{A} \cdot \cos \left(\phi+\tau+\frac{\pi}{2}-\phi\right)=r_{A} \cdot \cos \left(\frac{\pi}{2}+\tau\right) \\
=-r_{A} \cdot \sin \tau=-r_{A} \cdot \frac{s^{\prime}}{r_{A}}=-s^{\prime} \\
y_{T}=r_{A} \cdot \sin \left(\phi+\tau+\frac{\pi}{2}-\phi\right)=r_{A} \cdot \sin \left(\frac{\pi}{2}+\tau\right) \\
=r_{A} \cdot \cos \tau=r_{A} \cdot \frac{r_{0}+s}{r_{A}}=r_{0}+s
\end{array}\right.
$$

In the mobile system $x^{\prime} O y^{\prime}$ a Cartesian coordinates of the point contact $\mathrm{A}$ (belonging to the cam profile which rotated clockwise by angle $\varphi$ ) are given by the relations systems (29-30):

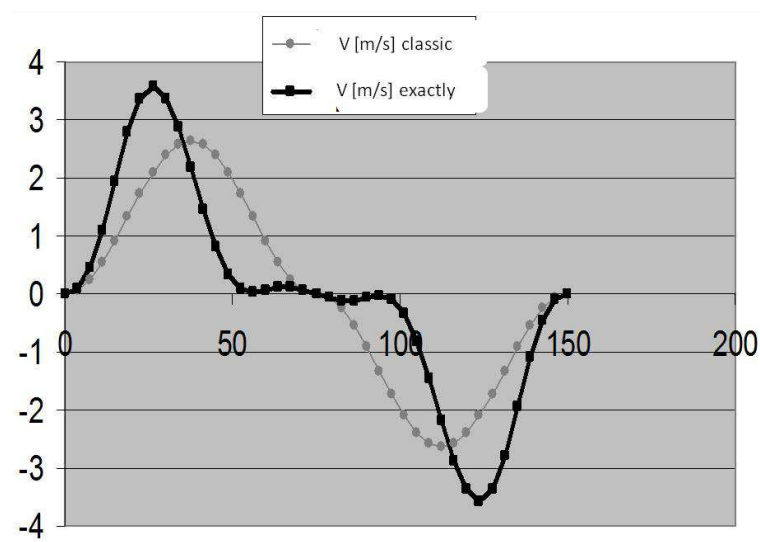

(a)

$$
\left\{\begin{array}{l}
x_{C}=r_{A} \cdot \cos \left(\phi+\tau+\frac{\pi}{2}-\phi+\phi\right)=r_{A} \cdot \cos \left(\frac{\pi}{2}+\tau+\phi\right) \\
=r_{A} \cdot \sin (-\phi-\tau)=-r_{A} \cdot \sin (\phi+\tau) \\
=-r_{A} \cdot(\sin \phi \cdot \cos \tau+\sin \tau \cdot \cos \phi) \\
=-r_{A} \cdot \frac{r_{0}+s}{r_{A}} \cdot \sin \phi-r_{A} \cdot \frac{s^{\prime}}{r_{A}} \cdot \cos \phi \\
=-\left(r_{0}+s\right) \cdot \sin \phi-s^{\prime} \cdot \cos \phi \\
y_{C}=r_{A} \cdot \sin \left(\phi+\tau+\frac{\pi}{2}-\phi+\phi\right)=r_{A} \cdot \sin \left(\frac{\pi}{2}+\tau+\phi\right) \\
=r_{A} \cdot \cos (-\phi-\tau)=r_{A} \cdot \cos (\phi+\tau) \\
=r_{A} \cdot(\cos \phi \cdot \cos \tau-\sin \tau \cdot \sin \phi) \\
=r_{A} \cdot \frac{r_{0}+s}{r_{A}} \cdot \cos \phi-r_{A} \cdot \frac{s^{\prime}}{r_{A}} \cdot \sin \phi=\left(r_{0}+s\right) \cdot \cos \phi-s^{\prime} \cdot \sin \phi
\end{array}\right.
$$

$\left\{\begin{array}{l}x_{C}=-s^{\prime} \cdot \cos \phi-\left(r_{0}+s\right) \cdot \sin \phi \\ y_{C}=\left(r_{0}+s\right) \cdot \cos \phi-s^{\prime} \cdot \sin \phi\end{array}\right.$

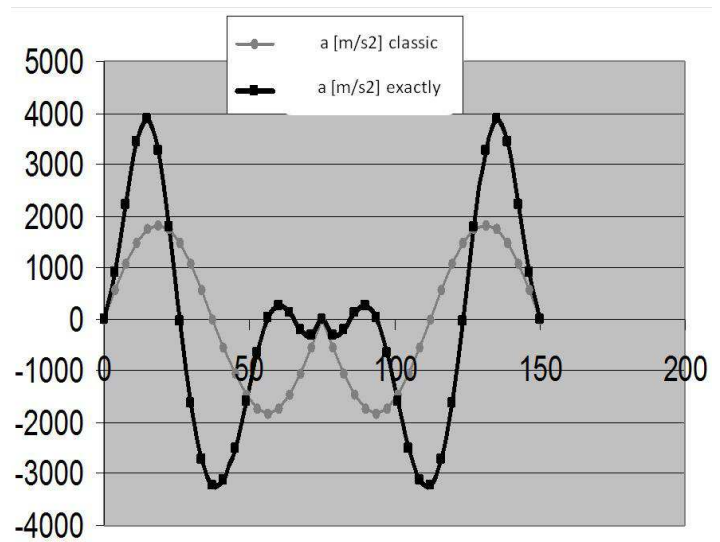

(b)

Fig. 2. The classical and dynamic (exactly) kinematics (a) Velocities (b) Accelerations of the follower

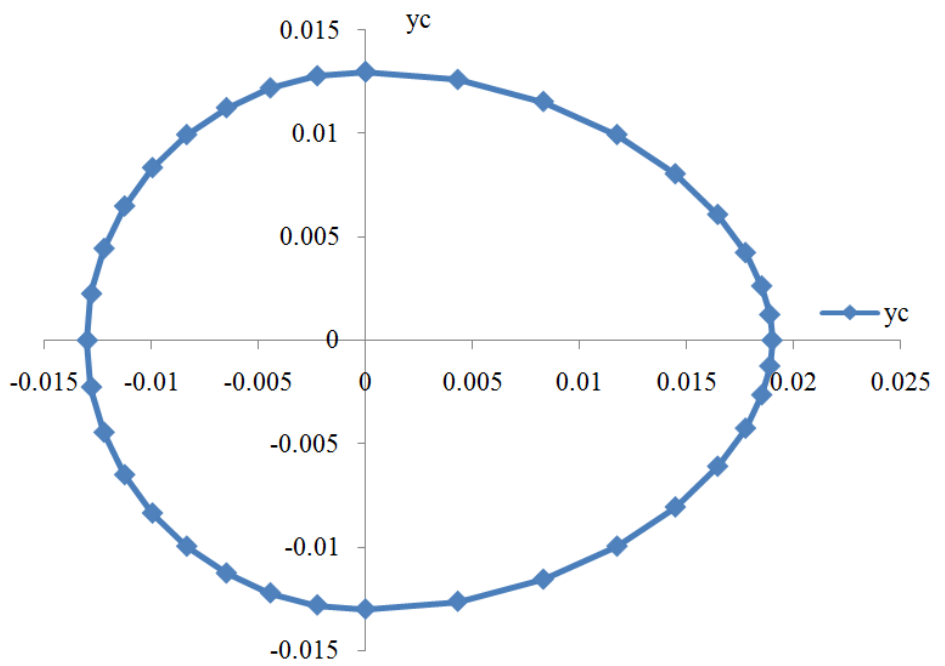

Fig. 3. A cosine profile of a normal classical cam 
Above, in the Fig. 3 it can be seen the cam profile to the classical module $\mathrm{C}$, for a law cosine, $\mathrm{h}=6$ $[\mathrm{mm}], \mathrm{r}_{0}=13[\mathrm{~mm}], \eta=6 \%$.

\section{Synthesis of the Distribution Mechanism \\ Module B}

In the Fig. 4 one can see the module B, with rotation cam and translated tappet with roll, in initial position and in some one position.

The $\alpha_{0}$ angle defines the base position of the vector $\bar{r}_{B 0}$ in $\mathrm{OCB}_{0}$ right triangle so that it can be written Equation 2.1-2.4:

$$
\begin{aligned}
& r_{B_{0}}=r_{0}+r_{b} \\
& s_{0}=\sqrt{r_{B_{0}}^{2}-e^{2}} \\
& \cos \alpha_{0}=\frac{e}{r_{B_{0}}} \\
& \sin \alpha_{0}=\frac{s_{0}}{r_{B_{0}}}
\end{aligned}
$$

The $\delta$ pressure angle (that occurs between normal $\mathrm{n}$ gone through the contact point $\mathrm{A}$ and a vertical line) has the known size given by the relations $(2.5-2.7)$ :

$$
\cos \delta=\frac{s_{0}+s}{\sqrt{\left(s_{0}+s\right)^{2}+\left(s^{\prime}-e\right)^{2}}}
$$

$$
\sin \delta=\frac{s^{\prime}-e}{\sqrt{\left(s_{0}+s\right)^{2}+\left(s^{\prime}-e\right)^{2}}}
$$

$\operatorname{tg} \delta=\frac{s^{\prime}-e}{s_{0}+s}$

The vector $\bar{r}_{A}$ can be determined directly with the relations (2.8-2.9):

$$
\begin{aligned}
& r_{A}^{2}=\left(e+r_{b} \cdot \sin \delta\right)^{2}+\left(s_{0}+s-r_{b} \cdot \cos \delta\right)^{2} \\
& r_{A}=\sqrt{\left(e+r_{b} \cdot \sin \delta\right)^{2}+\left(s_{0}+s-r_{b} \cdot \cos \delta\right)^{2}}
\end{aligned}
$$

It can directly determine the angle $\alpha_{\mathrm{A}}(2.10-2.11)$ :

$\cos \alpha_{A}=\frac{e+r_{b} \cdot \sin \delta}{r_{A}}$

$$
\sin \alpha_{A}=\frac{s_{0}+s-r_{b} \cdot \cos \delta}{r_{A}}
$$

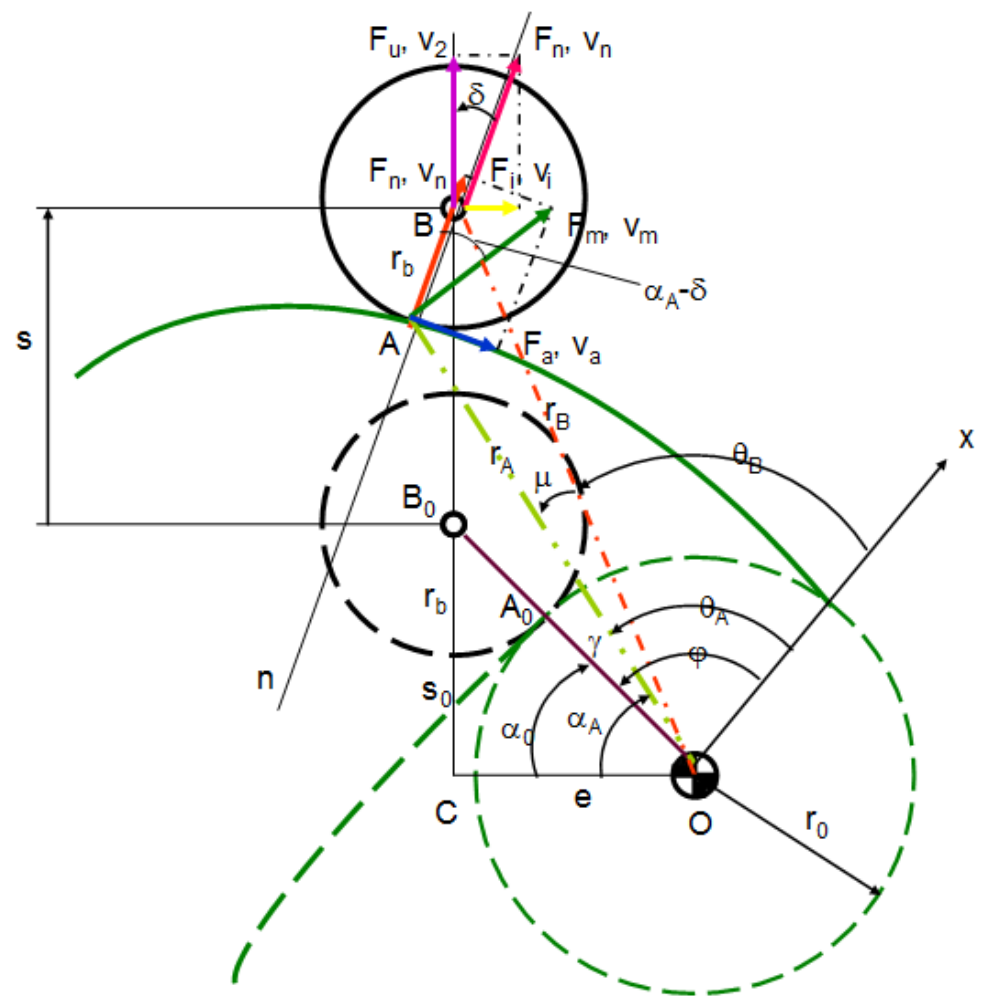

Fig. 4. Cam module B, with translated tappet with roll 
It can be now drawn directly the cam profile using polar coordinates $r_{\mathrm{A}}$ (known, see relation 2.9) and $\theta_{\mathrm{A}}$ (which is determined by relations 2.12-2.17):

$$
\begin{aligned}
& \gamma=\alpha_{A}-\alpha_{0} \\
& \cos \gamma=\cos \alpha_{A} \cdot \cos \alpha_{0}+\sin \alpha_{A} \cdot \sin \alpha_{0} \rightarrow \\
& \sin \gamma=\sin \alpha_{A} \cdot \cos \alpha_{0}-\cos \alpha_{A} \cdot \sin \alpha_{0} \\
& \theta_{A}=\phi-\gamma \\
& \cos \theta_{A}=\cos \phi \cdot \cos \gamma+\sin \phi \cdot \sin \gamma \\
& \sin \theta_{A}=\sin \phi \cdot \cos \gamma-\sin \gamma \cdot \cos \phi
\end{aligned}
$$

In the Fig. 5 it can be seen for the module B a cosine law cam profile calculated with parameters: $\mathrm{r}_{0}=13$ $[\mathrm{mm}], \mathrm{r}_{\mathrm{b}}=2[\mathrm{~mm}], \mathrm{h}=20[\mathrm{~mm}], \varphi_{\mathrm{u}}=60[\mathrm{deg}]$.

One has obtained in this mode a high yield for a mechanism with cam: $\eta=39 \%$.

It can be obtained the same yield (Fig. 6) with decreased stroke and up angle: $\mathrm{r}_{0}=13[\mathrm{~mm}], \mathrm{r}_{\mathrm{b}}=2$ $[\mathrm{mm}], \mathrm{h}=13[\mathrm{~mm}], \varphi_{\mathrm{u}}=45[\mathrm{deg}], \eta=39 \%$.

For such distribution mechanism works normally we must use the special adjustment valve spring: $x_{0}=9$ $[\mathrm{cm}], \mathrm{k}=500000[\mathrm{~N} / \mathrm{m}]$. Where $\mathrm{k}$ is the valve spring elastic coefficient and $\mathrm{x}_{0}$ is the valve spring preload.

It can be obtained a higher yield (Fig. 7) with the next parameters: $\mathrm{r}_{0}=15[\mathrm{~mm}], \mathrm{r}_{\mathrm{b}}=2[\mathrm{~mm}], \mathrm{h}=10[\mathrm{~mm}]$, $\varphi_{\mathrm{u}}=30$ [deg], $\eta=43 \%, \mathrm{k}=1500000[\mathrm{~N} / \mathrm{m}], \mathrm{x}_{0}=5[\mathrm{~cm}]$.

Although spring used is extremely hard to have a good dynamic in operation (Fig. 8), there's need to reduce its camshaft rotation speed three times.

But for such distribution mechanism may work must be used a triple cam.

\section{Exact Kinematics Module B}

For determination of exact kinematics one uses the next relations $(2.18-2.45)$ :

$$
\begin{aligned}
& r_{B}^{2}=e^{2}+\left(s_{0}+s\right)^{2} \\
& r_{B}=\sqrt{r_{B}^{2}} \\
& \cos \alpha_{B} \equiv \sin \tau=\frac{e}{r_{B}} \\
& \sin \alpha_{B} \equiv \cos \tau=\frac{s_{0}+s}{r_{B}} \\
& \cos (\delta+\tau)=\cos \delta \cdot \cos \tau-\sin \delta \cdot \sin \tau
\end{aligned}
$$

$$
\begin{aligned}
& r_{A}^{2}=r_{B}^{2}+r_{b}^{2}-2 \cdot r_{b} \cdot r_{B} \cdot \cos (\delta+\tau) \\
& \cos \mu=\frac{r_{A}^{2}+r_{B}^{2}-r_{b}^{2}}{2 \cdot r_{A} \cdot r_{B}} \\
& \sin (\delta+\tau)=\sin \delta \cdot \cos \tau+\sin \tau \cdot \cos \delta \\
& \sin \mu=\frac{r_{b}}{r_{A}} \cdot \sin (\delta+\tau) \\
& \alpha_{A}=\alpha_{B}-\mu \\
& \dot{\alpha}_{A}=\dot{\alpha}_{B}-\dot{\mu}
\end{aligned}
$$

$$
-\sin \alpha_{B} \cdot \dot{\alpha}_{B}=-\frac{e \cdot \dot{r}_{B}}{r_{B}^{2}}
$$

$\dot{\alpha}_{B}=\frac{e \cdot r_{B} \cdot \dot{r}_{B}}{\left(s_{0}+s\right) \cdot r_{B}^{2}}$

$\left\{\begin{array}{l}2 \cdot r_{B} \cdot \dot{r}_{B}=2 \cdot\left(s_{0}+s\right) \cdot \dot{s} \\ r_{B} \cdot \dot{r}_{B}=\left(s_{0}+s\right) \cdot \dot{s}\end{array}\right.$

$\dot{\alpha}_{B}=\frac{e \cdot\left(s_{0}+s\right) \cdot \dot{s}}{\left(s_{0}+s\right) \cdot r_{B}^{2}}=\frac{e \cdot \dot{s}}{r_{B}^{2}}$

$\left\{\begin{array}{l}2 \cdot \dot{r}_{A} \cdot r_{B} \cdot \cos \mu+2 \cdot r_{A} \cdot \dot{r}_{B} \cdot \cos \mu \\ -2 \cdot r_{A} \cdot r_{B} \cdot \sin \mu \cdot \dot{\mu}=2 \cdot r_{A} \cdot \dot{r}_{A}+2 \cdot r_{B} \cdot \dot{r}_{B}\end{array}\right.$

$\left\{\begin{array}{l}2 \cdot r_{A} \cdot \dot{r}_{A}=2 \cdot r_{B} \cdot \dot{r}_{B}-2 \cdot r_{b} \cdot \dot{r}_{B} \cdot \cos (\delta+\tau) \\ +2 \cdot r_{b} \cdot r_{B} \cdot \sin (\delta+\tau) \cdot(\dot{\delta}+\dot{\tau})\end{array}\right.$

$\delta^{\prime}=\frac{s^{\prime \prime} \cdot\left(s_{0}+e\right)-s^{\prime} \cdot\left(s^{\prime}-e\right)}{\left(s_{0}+s\right)^{2}+\left(s^{\prime}-e\right)^{2}}$

$\dot{\delta}=\delta^{\prime} \cdot \omega$

$\dot{\tau}=-\dot{\alpha}_{B}=-\frac{e \cdot \dot{s}}{r_{B}^{2}}$

$\dot{\mu}=\frac{\dot{r}_{A} \cdot r_{B} \cdot \cos \mu+r_{A} \cdot \dot{r}_{B} \cdot \cos \mu-r_{A} \cdot \dot{r}_{A}-r_{B} \cdot \dot{r}_{B}}{r_{A} \cdot r_{B} \cdot \sin \mu}$

$\dot{\theta}_{A}=\dot{\phi}-\dot{\gamma}=\omega-\dot{\alpha}_{A}$

$\cos \alpha_{A}=\frac{e \cdot \sqrt{\left(s_{0}+s\right)^{2}+\left(s^{\prime}-e\right)^{2}}+r_{b} \cdot\left(s^{\prime}-e\right)}{r_{A} \cdot \sqrt{\left(s_{0}+s\right)^{2}+\left(s^{\prime}-e\right)^{2}}}$ 


$$
\begin{aligned}
& \sin \alpha_{A}=\frac{\left(s_{0}+s\right) \cdot\left[\sqrt{\left(s_{0}+s\right)^{2}+\left(s^{\prime}-e\right)^{2}}-r_{b}\right]}{r_{A} \cdot \sqrt{\left(s_{0}+s\right)^{2}+\left(s^{\prime}-e\right)^{2}}} \\
& \cos \left(\alpha_{A}-\delta\right)=\frac{\left(s_{0}+s\right) \cdot s^{\prime}}{r_{A} \cdot \sqrt{\left(s_{0}+s\right)^{2}+\left(s^{\prime}-e\right)^{2}}}=\frac{s^{\prime}}{r_{A}} \cdot \cos \delta \\
& \cos \left(\alpha_{A}-\delta\right) \cdot \cos \delta=\frac{s^{\prime}}{r_{A}} \cdot \cos ^{2} \delta \\
& \cos \mu= \\
& {\left[\left(s_{0}+s\right)^{2}+e^{2}\right] \cdot \sqrt{\left(s_{0}+s\right)^{2}+\left(s^{\prime}-e\right)^{2}}} \\
& \frac{-r_{b} \cdot\left[\left(s_{0}+s\right)^{2}+e^{2}-e \cdot s^{\prime}\right]}{r_{A} \cdot r_{B} \cdot \sqrt{\left(s_{0}+s\right)^{2}+\left(s^{\prime}-e\right)^{2}}} \\
& \sin \mu=\frac{r_{b} \cdot\left(s_{0}+s\right) \cdot s^{\prime}}{r_{A} \cdot r_{B} \cdot \sqrt{\left(s_{0}+s\right)^{2}+\left(s^{\prime}-e\right)^{2}}}
\end{aligned}
$$

yc

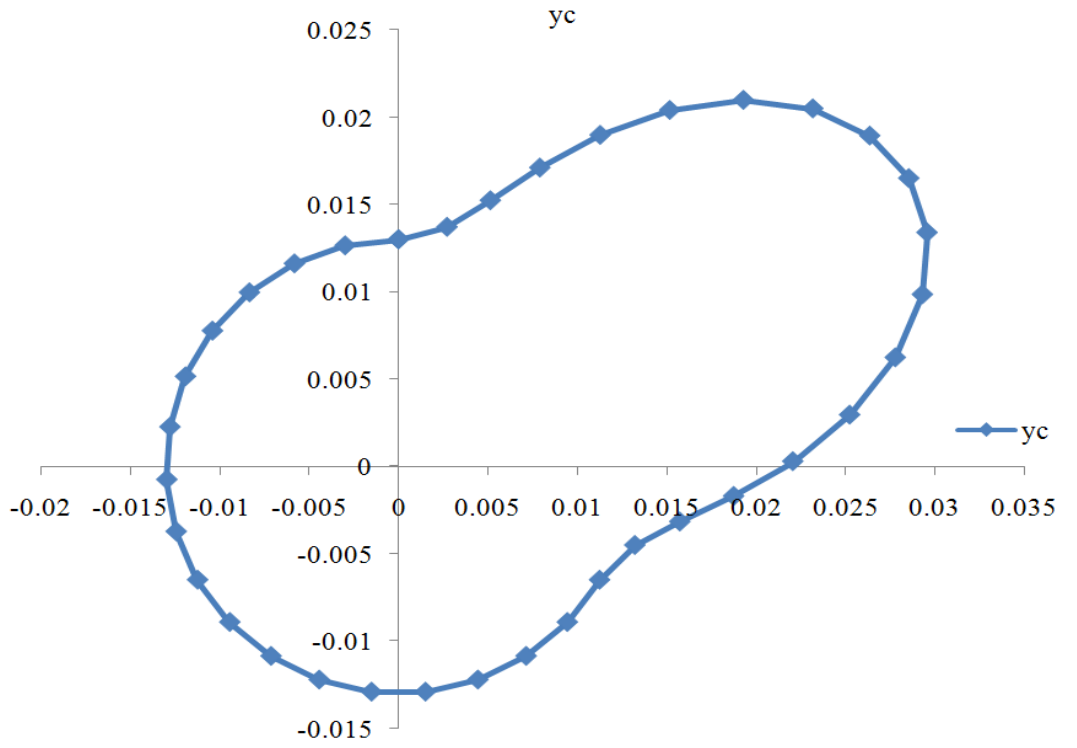

Fig. 5. Cam module B profile cosine law, with translated tappet with roll; $\mathrm{r}_{0}=13[\mathrm{~mm}], \mathrm{r}_{\mathrm{b}}=2[\mathrm{~mm}], \mathrm{h}=20[\mathrm{~mm}], \varphi_{\mathrm{u}}=60$ [deg], $\eta=39 \%$

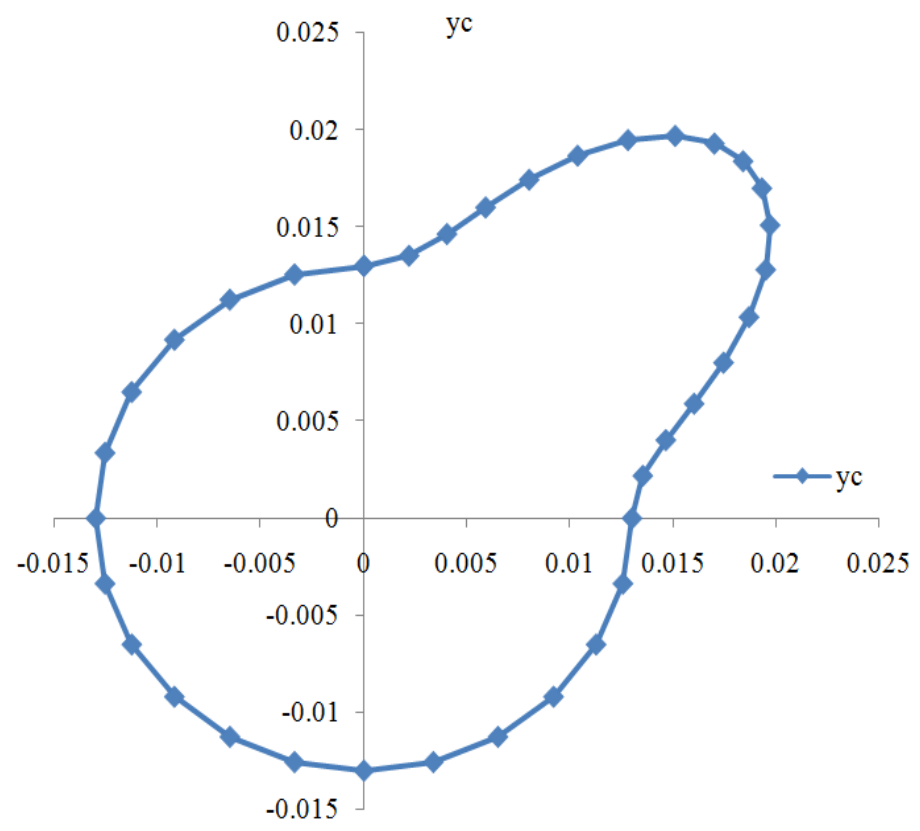

Fig. 6. Cam module B profile cosine law, with translated tappet with roll; $r_{0}=13[\mathrm{~mm}], \mathrm{r}_{\mathrm{b}}=2[\mathrm{~mm}], \mathrm{h}=13[\mathrm{~mm}], \varphi_{\mathrm{u}}=45$ [deg], $\eta=39 \%$ 


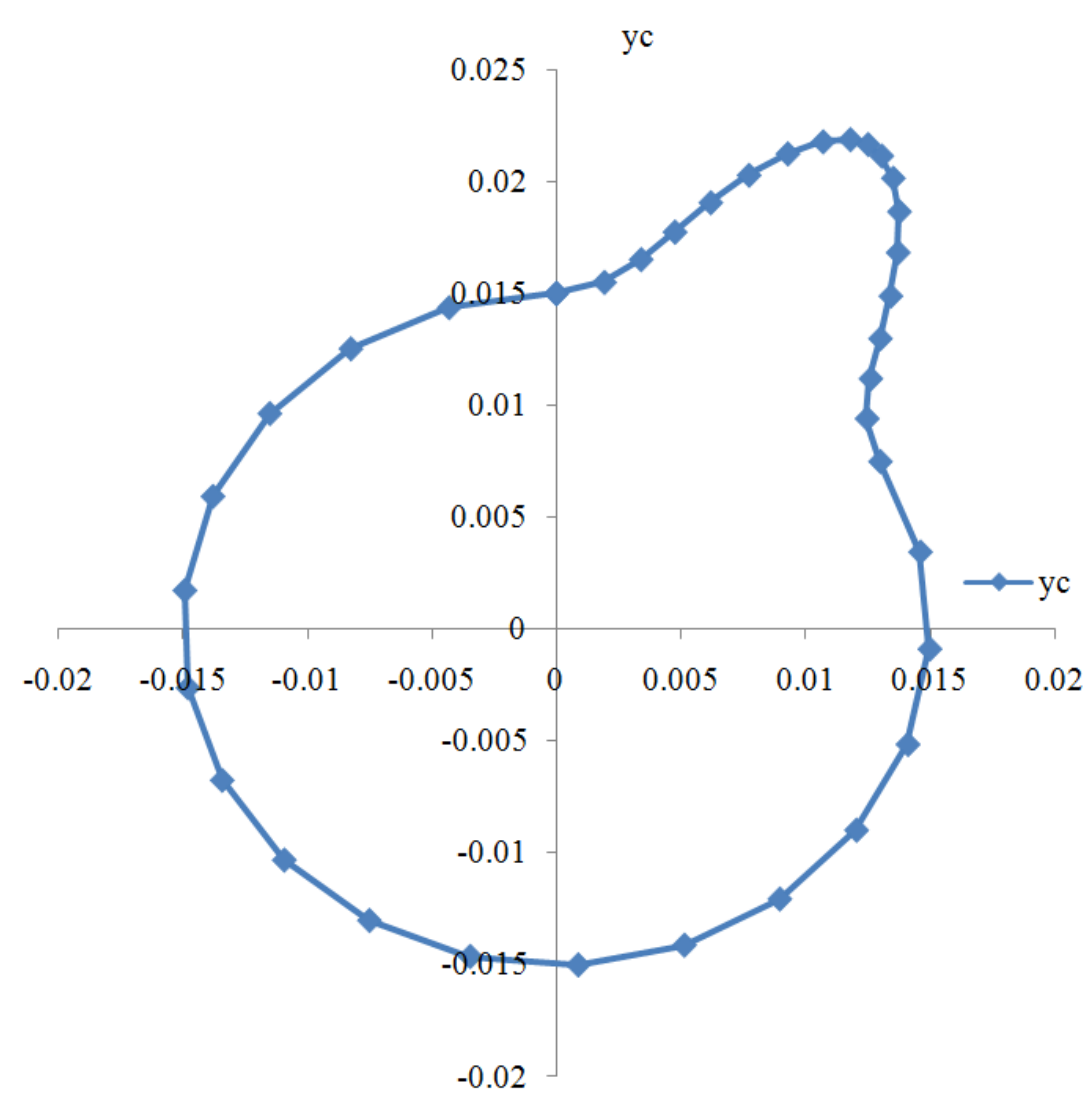

Fig. 7. Cam module B profile cosine law, with translated tappet with roll; $\mathrm{r}_{0}=15[\mathrm{~mm}], \mathrm{r}_{\mathrm{b}}=2[\mathrm{~mm}], \mathrm{h}=10[\mathrm{~mm}], \varphi_{\mathrm{u}}=30$ [deg], $\eta=43 \%$

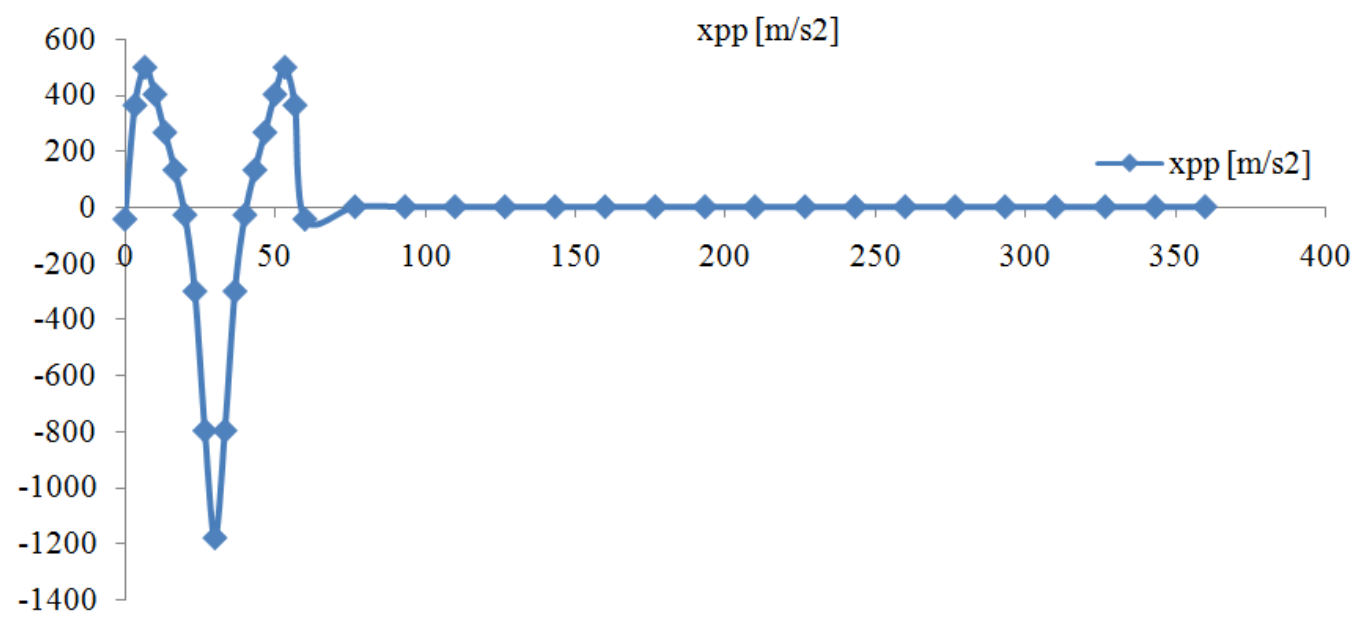

Fig. 8. Cam module B dynamics (cosine law, with translated tappet with roll: $\mathrm{r}_{0}=15[\mathrm{~mm}], \mathrm{r}_{\mathrm{b}}=2[\mathrm{~mm}], \mathrm{h}=10[\mathrm{~mm}], \varphi_{\mathrm{u}}=30[\mathrm{deg}]$, $\eta=43 \%)$; the tappet acceleration in relation of $\varphi$ angle

\section{Determination of Dynamic Coefficient D}

The dynamic coefficient at the module B takes the form (2.46), where $\cos ^{2} \delta$ is given by relation (2.47) and $\theta_{A}^{I}$ is obtained from expression (2.48):

$$
D=\theta_{A}^{I} \cdot \cos ^{2} \delta
$$

$\cos ^{2} \delta=\frac{\left(s_{0}+s\right)^{2}}{\left(s_{0}+s\right)^{2}+\left(s^{\prime}-e\right)^{2}}$ 


$$
\begin{aligned}
& \theta_{A}^{I}=\left[\left(s_{0}+s\right)^{2}+e^{2}-e \cdot s^{\prime}-r_{b} \cdot \sqrt{\left(s_{0}+s\right)^{2}+\left(s^{\prime}-e\right)^{2}}\right] . \\
& \left\{\left[\left(s_{0}+s\right)^{2}+\left(s^{\prime}-e\right)^{2}\right] \cdot \sqrt{\left(s_{0}+s\right)^{2}+\left(s^{\prime}-e\right)^{2}}\right. \\
& \left.+r_{b} \cdot\left[s^{\prime \prime} \cdot\left(s_{0}+s\right)-s^{\prime} \cdot\left(s^{\prime}-e\right)-\left(s_{0}+s\right)^{2}-\left(s^{\prime}-e\right)^{2}\right]\right\} \\
& /\left[\left(s_{0}+s\right)^{2}+\left(s^{\prime}-e\right)^{2}\right] /\left\{\left[\left(s_{0}+s\right)^{2}+e^{2}+r_{b}^{2}\right] \cdot\right. \\
& \left.\sqrt{\left(s_{0}+s\right)^{2}+\left(s^{\prime}-e\right)^{2}}-2 \cdot r_{b} \cdot\left[\left(s_{0}+s\right)^{2}+e^{2}-e \cdot s^{\prime}\right]\right\}
\end{aligned}
$$

\section{Synthesis of the Distribution Mechanism Module F}

In the Fig. 9 one can see the module F, with rotation cam and rotated tappet with roll, in initial position and in some one position.

A study very precisely (exactly) is possible only when we analyze what happens in point $A$ (the point of contact between cam and the roller of the tappet). Point $A$ is defined by the vector of length (module) $r_{A}$ and $\theta_{\mathrm{A}}$ position angle, measured from the axis $\mathrm{Ox}$ and or $\alpha_{\mathrm{A}}$ angle, measured from the axis OD (Fig. 9).

In the same mode is defined position of the point $\mathrm{B}$ (roll center), by the vector $\bar{r}_{B}$, which is positioned in turn by the angle $\theta_{\mathrm{B}}$ to the axis $\mathrm{Ox}$ and $\alpha_{\mathrm{B}}$ angle to the axis OD and has length $\mathrm{r}_{\mathrm{B}}$. Between the two presented vectors $\left(\bar{r}_{A}\right.$ and, $\left.\bar{r}_{B}\right)$ is forming an angle $\mu$. The angle $\alpha_{0}$ defines the position, basic (initial) of the vector $r_{\mathrm{A}}$ in $\mathrm{ODB}_{0}$ right triangle, as measured from the axis OD. The rotation of the cam (the shaft distribution), given by the $\varphi$ angle, is measured from the axis $O x$, to the
$\bar{r}_{B 0}$ vector. As the camshaft rotates with $\varphi$ angle, the $\bar{r}_{A}$ vector is rotated by the angle $\theta_{\mathrm{A}}$ and between the two angles $\theta_{\mathrm{A}}$ and $\varphi$ there is a mismatch (a phase shift) which is noted in Fig. 9 with $\gamma ; \gamma$ phase shift occurs and between $\alpha_{\mathrm{A}}$ and $\alpha_{0}$ angles, which helps us to determine the exact value of its. The length (radius) of the tappet, $\mathrm{DB}=\mathrm{b}$, in the initial position $\mathrm{DB}_{0}$ makes with OD axis the angle $\psi_{0}$ constant, which can be determined easily together with $\alpha_{0}$ from the triangle $\mathrm{ODB}_{0}$ (with: $\mathrm{OD}=\mathrm{d}, \mathrm{DB}=\mathrm{DB}_{0}=\mathrm{b}, \mathrm{OB}_{0}=\mathrm{r}_{0}+\mathrm{r}_{\mathrm{b}}$ known; where $r_{0}$ is the radius of the basic circle on the rotary cam and $r_{b}$ is the roller radius of the follower).

From initial position until the current position, the follower rotates around the point $\mathrm{D}$ with a known $\psi$ angle. This $\psi$ angle, is given by the law of motion of pusher and is a function of the $\varphi$ angle. $\psi$ is known together with its derivatives: $\psi^{\prime}, \psi^{\prime \prime}, \psi^{\prime \prime}$. In general it is easier to express the movement of the follower in function of axis OD, so occurs the angle $\psi_{2}=\psi_{0}+\psi$ (with: $\psi_{2}^{\prime}=\psi^{\prime}, \psi_{2}^{\prime \prime}=\psi^{\prime \prime}$ ).

From ODB triangle, with known lengths $\mathrm{OD}=\mathrm{d}, \mathrm{DB}$ $=\mathrm{b}$ and $\psi_{2}$ angle, one determines the length $\mathrm{OB}=\mathrm{r}_{\mathrm{B}}$, the $\mathrm{DOB}=\alpha_{\mathrm{B}}$ angle and the OBD $=\beta_{2}$ angle (Fig. 10). Angle $\mathrm{B}$ sought, with angles $\beta_{2}$ and $\tau$, totals 180 [deg]; and $\tau+\delta=90$ [deg]; With delta known, results $\tau$ and the $B$ angle. Now, with $r_{B}, r_{b}$ and $B$ known (from the triangle OBA) we can determine $r_{A}$ and $\mu$.

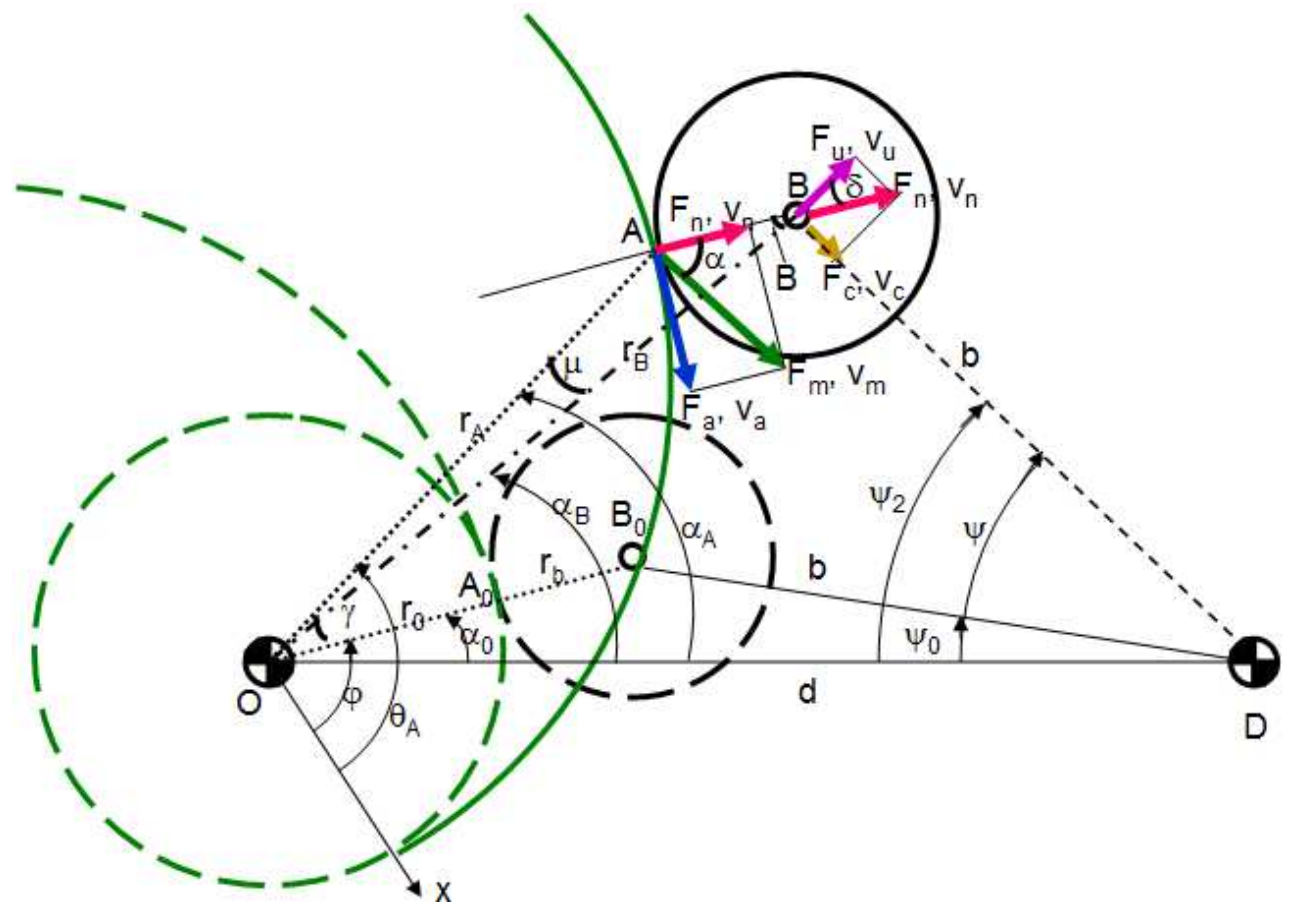

Fig. 9. Mechanism with rotating cam and rotating tappet with roll 


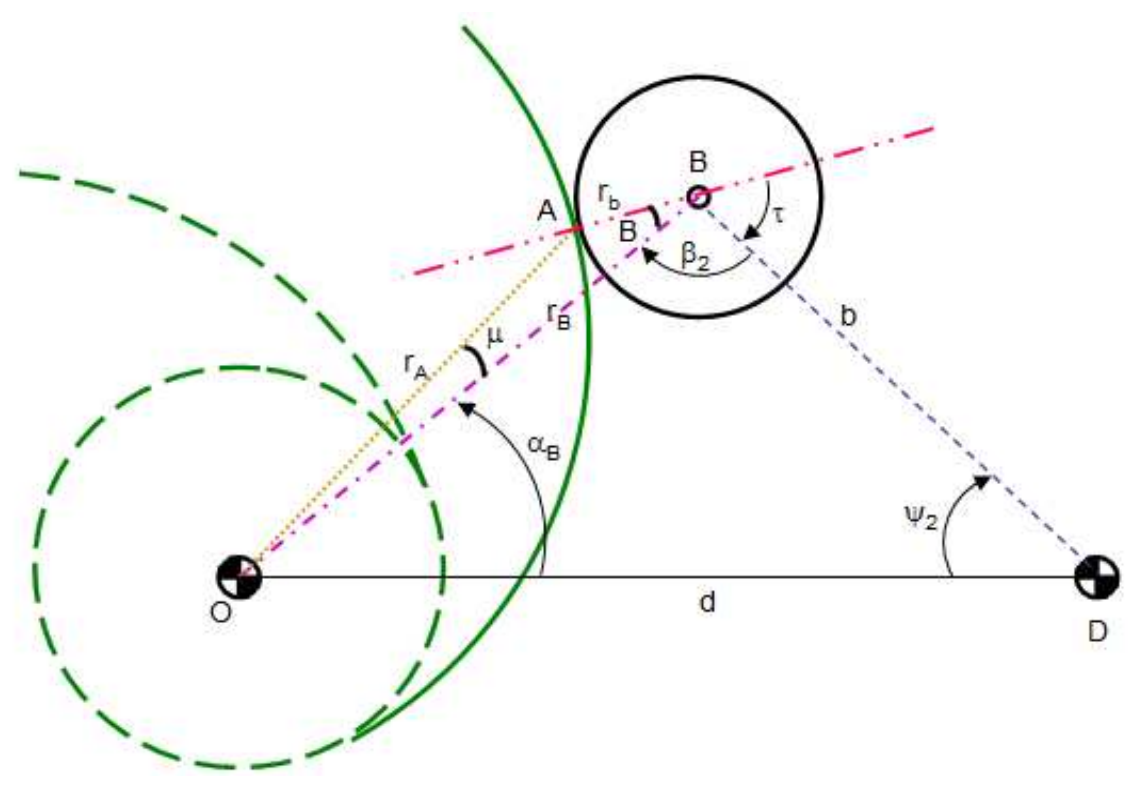

Fig. 10. Determination of angle B

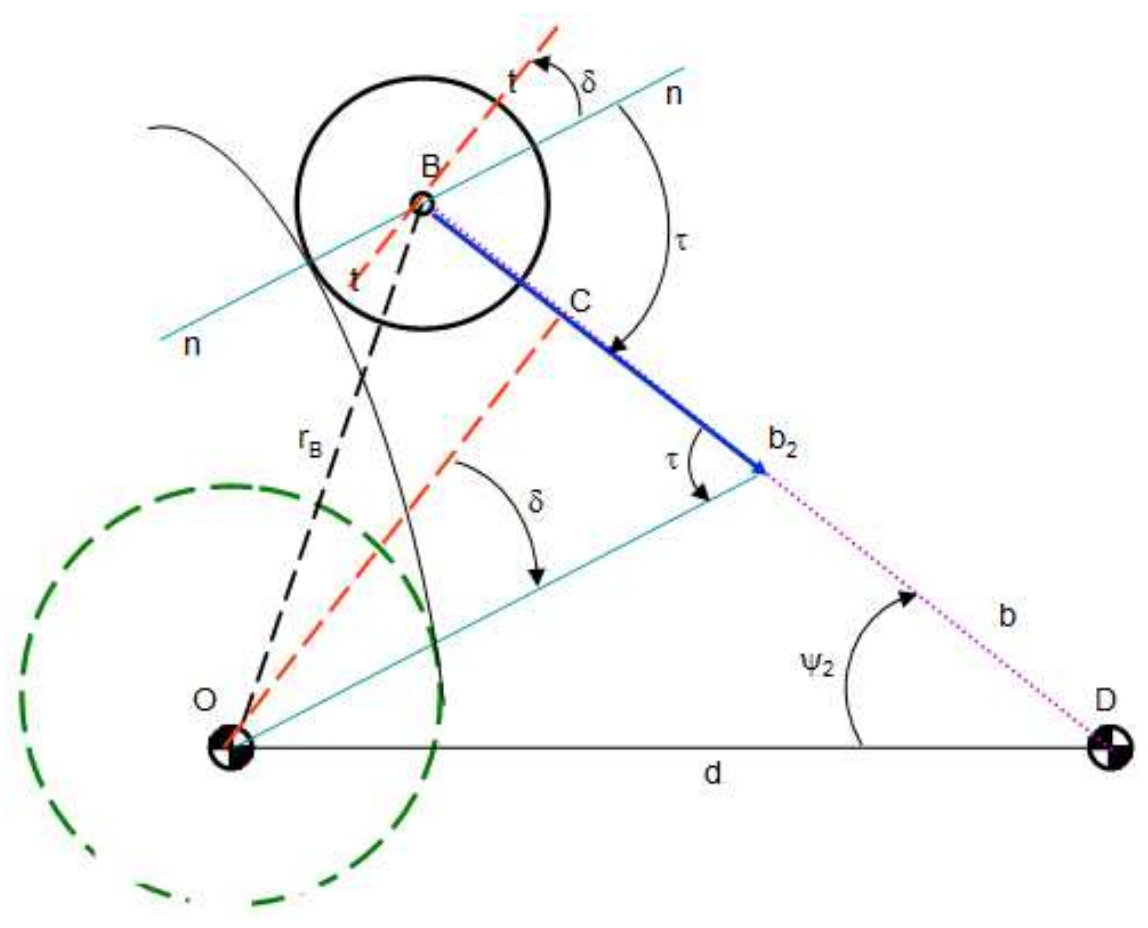

Fig. 11. Determination of the pressure angle, $\delta$

\section{Synthesis of the Cam Profile}

$$
\gamma=\alpha_{A}-\alpha_{0}
$$

Now it can make the synthesis of the cam profile $\theta_{A}=\phi+\gamma$ with the next relationships (3.1-3.4):

$\alpha_{A}=\alpha_{B}+\mu$

$\left\{\begin{array}{l}x_{A}=r_{A} \cdot \cos \theta_{A} \\ y_{A}=r_{A} \cdot \sin \theta_{A}\end{array}\right.$ 
To do this, it must determine first the pressure $\delta$ angle.

\section{Determination of the Pressure $\delta$ Angle}

Now one presents shortly one known method to determine the pressure angle $\delta$ at the rotary cam and rocking tappet with roll (Module F, Fig. 11).

The pressure angle is defined between two straight lines: $n-n$ and $t-t$ (the line $n-n$, pass through the points $\mathrm{A}$ and $\mathrm{B}$ and is perpendicular in $\mathrm{A}$ at the two profiles in contact; the line $t-t$, pass through the point $B$ and is perpendicular in $\mathrm{B}$ on the line $\mathrm{DB}$ which represent the tappet axis).

One builds (scale) the speed triangle rotated with 90 [deg] (Fig. 11); the cam velocity in $\mathrm{B}\left(\mathrm{v}_{\mathrm{B} 1}\right)$ appears along the $\mathrm{BO}$, oriented from $\mathrm{B}$ to $\mathrm{O}$, the reduced velocity of the tappet in $B$ point $\left(v_{B 2}\right)$ appears along the $\mathrm{BD}$, oriented from $\mathrm{B}$ to $\mathrm{b}_{2}$ and the sliding between profiles velocity in the point $\mathrm{B}\left(\mathrm{v}_{\mathrm{B} 2 \mathrm{~B} 1}\right)$ appears along the $n-n$ line, oriented from $\mathrm{O}$ to $b_{2}$.

It takes the pole of the fold (rotated) speeds, $\mathrm{P}_{\mathrm{v}}$, in $\mathrm{B}$ and the velocities scale $\mathrm{k}_{\mathrm{v}}=\mathrm{k}_{1} \cdot \omega_{1} \cdot\left((\mathrm{BO})=\left(\mathrm{P}_{\mathrm{v}} \mathrm{b}_{1}\right)=\right.$ $\mathrm{v}_{\mathrm{B} 1} /\left[\mathrm{k}_{1} \cdot \omega_{1}\right] ;\left(\mathrm{Bb}_{2}\right)=\left(\mathrm{P}_{\mathrm{v}} \mathrm{b}_{2}\right)=\mathrm{v}_{\mathrm{B} 2} /\left[\mathrm{k}_{1} \cdot \omega_{1}\right] ;\left(\mathrm{Ob}_{2}\right)=\left(\mathrm{b}_{1} \mathrm{~b}_{2}\right)=$ $\left.\mathrm{v}_{\mathrm{B} 2 \mathrm{~B} 1} /\left[\mathrm{k}_{1} \cdot \omega_{1}\right]\right)$. It determines the lengths with the relationships 3.5 and 3.6:

$$
\left\{\begin{array}{l}
D B=b ; B b_{2}=\frac{v_{B_{2}}}{\omega_{1}}=b \cdot \psi^{\prime} ; C D=d \cdot \cos \psi_{2} \\
O C=d \cdot \sin \psi_{2} ; b_{2} D=b-b \cdot \psi^{\prime} \\
C b_{2}=C D-b_{2} D=d \cdot \cos \psi_{2}-\left(b-b \cdot \psi^{\prime}\right) \\
=d \cdot \cos \psi_{2}+b \cdot \psi^{\prime}-b
\end{array}\right.
$$

From the $\mathrm{ODb}_{2}$ triangle, one determines the length $\mathrm{Ob}_{2}$, (relation 3.6):

$$
\begin{aligned}
& O b_{2}=R A D= \\
& =\sqrt{d^{2}+\left(b-b \cdot \psi^{\prime}\right)^{2}-2 \cdot d \cdot\left(b-b \cdot \psi^{\prime}\right) \cdot \cos \psi_{2}}
\end{aligned}
$$

With the known lengths one can determine now the trigonometric functions of the $\delta$ pressure angle, with the relationships (3.7-3.9):

$$
\begin{aligned}
& \sin \delta=\frac{d \cdot \cos \psi_{2}+b \cdot \psi^{\prime}-b}{\sqrt{d^{2}+\left(b-b \cdot \psi^{\prime}\right)^{2}-2 \cdot d \cdot\left(b-b \cdot \psi^{\prime}\right) \cdot \cos \psi_{2}}}= \\
& =\frac{d \cdot \cos \psi_{2}+b \cdot \psi^{\prime}-b}{R A D} \\
& \cos \delta=\frac{d \cdot \sin \psi_{2}}{\sqrt{d^{2}+\left(b-b \cdot \psi^{\prime}\right)^{2}-2 \cdot d \cdot\left(b-b \cdot \psi^{\prime}\right) \cdot \cos \psi_{2}}}= \\
& =\frac{d \cdot \sin \psi_{2}}{R A D} \\
& \operatorname{tg} \delta=\frac{d \cdot \cos \psi_{2}+b \cdot \psi^{\prime}-b}{d \cdot \sin \psi_{2}}
\end{aligned}
$$

\section{Determination of the Pressure $\alpha$ Angle}

Further $\alpha$ pressure-angle is determined (where $\alpha$ is an additional pressure-angle), to the rotary cam and rotating follower with roll (Module F). This angle appears between the direction $n-n$ and right segment AA', perpendicular in A on OA (Fig. 12).

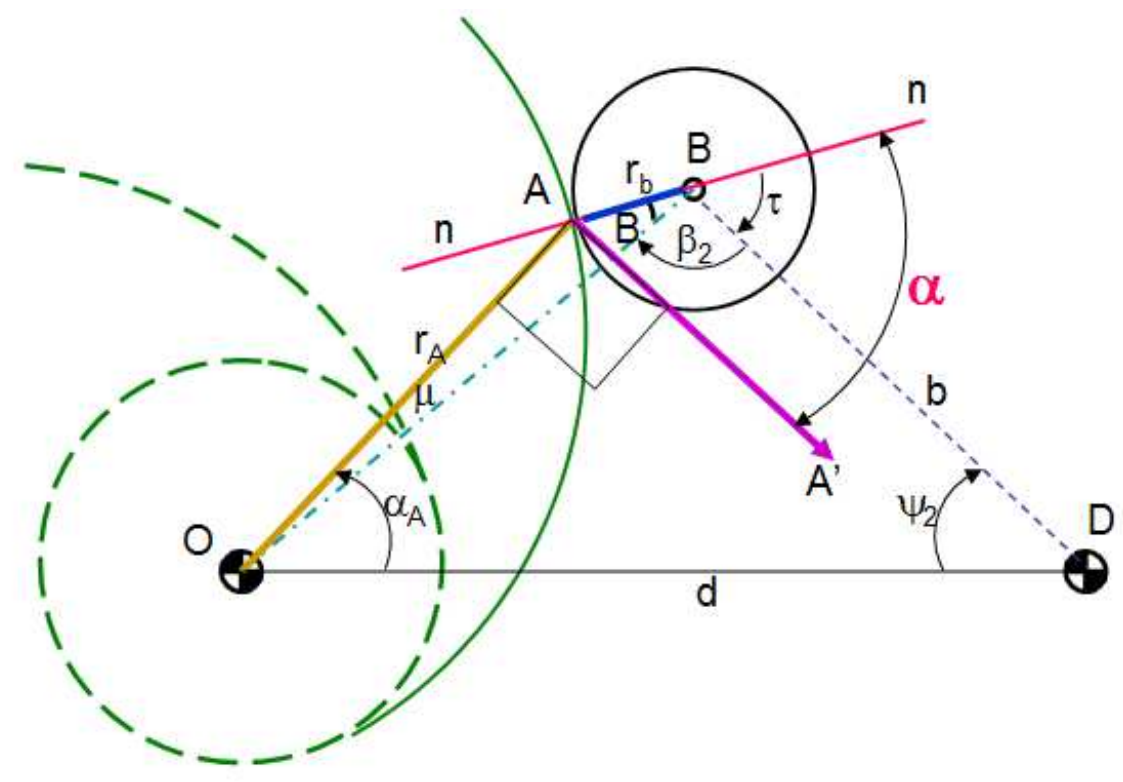

Fig. 12. Determination of the additionally pressure angle $\alpha$ 
From some triangle $\mathrm{OAB}$ was expressed and $\mathrm{OAB}$ angle (Fig. 12). From the angle OAB directly subtract $90^{\circ}$ and get extra pressure $\alpha$ angle. The calculation formulas are (3.10-3.20):

$\alpha=O A B-90$

$\sin \alpha=\sin (O A B-90)=\epsilon$

$=-\sin (90-O A B)=-\cos (O A B)$

$\cos \alpha=\cos (O A B-90)=$

$=\cos (90-O A B)=\sin (O A B)=\frac{r_{B}}{r_{A}} \cdot \sin B$

$\cos \alpha_{B}=\frac{d-b \cdot \cos \psi_{2}}{r_{B}}$

$\sin \alpha_{B}=\frac{b \cdot \sin \psi_{2}}{r_{B}}$

$\sin \delta=\frac{d \cdot \cos \psi_{2}+b \cdot \psi^{\prime}-b}{R A D}$

$\cos \delta=\frac{d \cdot \sin \psi_{2}}{R A D}$

$\left\{\begin{array}{l}\sin \left(\delta+\psi_{2}\right)=\sin \delta \cdot \cos \psi_{2}+\sin \psi_{2} \cdot \cos \delta= \\ =\frac{d \cdot \cos \psi_{2}+b \cdot \psi^{\prime}-b}{R A D} \cdot \cos \psi_{2}+ \\ +\frac{d \cdot \sin \psi_{2} \cdot \sin \psi_{2}}{R A D}=\frac{d-b \cdot \cos \psi_{2} \cdot\left(1-\psi^{\prime}\right)}{R A D}\end{array}\right.$

$\left\{\begin{array}{l}\cos \left(\delta+\psi_{2}\right)=\cos \delta \cdot \cos \psi_{2}-\sin \delta \cdot \sin \psi_{2}= \\ d \cdot \sin \psi_{2} \cdot \cos \psi_{2}-d \cdot \cos \psi_{2} \cdot \sin \psi_{2} \\ =\frac{-b \cdot \psi^{\prime} \cdot \sin \psi_{2}+b \cdot \sin \psi_{2}}{R A D}= \\ =\frac{b \cdot \sin \psi_{2} \cdot\left(1-\psi^{\prime}\right)}{R A D}\end{array}\right.$

$\left\{\begin{array}{l}\sin B=\sin \left(\delta+\psi_{2}\right) \cdot \sin \alpha_{B}-\cos \left(\delta+\psi_{2}\right) \cdot \cos \alpha_{B}= \\ =\frac{d \cdot b \cdot \sin \psi_{2}-b^{2} \cdot \sin \psi_{2} \cdot \cos \psi_{2} \cdot\left(1-\psi^{\prime}\right)}{r_{B} \cdot R A D}+ \\ +\frac{b^{2} \cdot \cos \psi_{2} \cdot \sin \psi_{2} \cdot\left(1-\psi^{\prime}\right)-d \cdot b \cdot \sin \psi_{2} \cdot\left(1-\psi^{\prime}\right)}{r_{B} \cdot R A D}= \\ =\frac{d \cdot b \cdot \sin \psi_{2} \cdot \psi^{\prime}}{r_{B} \cdot R A D}=\frac{d \cdot \sin \psi_{2}}{R A D} \cdot \frac{b \cdot \psi^{\prime}}{r_{B}}=\frac{b \cdot \psi^{\prime}}{r_{B}} \cdot \cos \delta \\ \sin B=\frac{b \cdot \psi^{\prime} \cdot \cos \delta}{r_{B}}\end{array}\right.$

$$
\left\{\begin{array}{l}
\cos \alpha=\frac{r_{B}}{r_{A}} \cdot \sin B=\frac{r_{B}}{r_{A}} \cdot \frac{b \cdot \psi^{\prime} \cdot \cos \delta}{r_{B}}= \\
=\frac{b \cdot \psi^{\prime} \cdot \cos \delta}{r_{A}} \\
\cos \alpha=\frac{b \cdot \psi^{\prime}}{r_{A}} \cdot \cos \delta
\end{array}\right.
$$

The $\cos \alpha$ can be expressed in a simplified form (see the relation 3.20).

\section{Basic Kinematics of Module F}

Below are presented a few parameters determining the kinematics (which constitutes the basis of this mechanism); relations: 3.21-3.56:

$\cos \psi_{0}=\frac{b^{2}+d^{2}-\left(r_{0}+r_{b}\right)^{2}}{2 \cdot b \cdot d}$

$\psi_{2}=\psi+\psi_{0}$

$R A D=\sqrt{d^{2}+b^{2} \cdot\left(1-\psi^{\prime}\right)^{2}-2 \cdot b \cdot d \cdot\left(1-\psi^{\prime}\right) \cdot \cos \psi_{2}}$

$\sin \delta=\frac{d \cdot \cos \psi_{2}+b \cdot \psi^{\prime}-b}{R A D}$

$\cos \delta=\frac{d \cdot \sin \psi_{2}}{R A D}$

$\operatorname{tg} \delta=\frac{d \cdot \cos \psi_{2}+b \cdot \psi^{\prime}-b}{d \cdot \sin \psi_{2}}$

$\delta^{\prime}=\frac{b \cdot \psi^{\prime \prime}-d \cdot \sin \psi_{2} \cdot \psi^{\prime}-d \cdot \operatorname{tg} \delta \cdot \cos \psi_{2} \cdot \psi^{\prime}}{d \cdot \sin \psi_{2}} \cdot \cos ^{2} \delta$

$r_{B}^{2}=b^{2}+d^{2}-2 \cdot b \cdot d \cdot \cos \psi_{2}$

$r_{B}=\sqrt{r_{B}^{2}}$

$r_{B}^{I}=\frac{b \cdot d \cdot \sin \psi_{2} \cdot \psi^{\prime}}{r_{B}}$

$\cos \alpha_{B}=\frac{d^{2}+r_{B}^{2}-b^{2}}{2 \cdot d \cdot r_{B}}$

$\sin \alpha_{B}=\frac{b \cdot \sin \psi_{2}}{r_{B}}$

$\alpha_{B}^{I}=\frac{d^{2}-b^{2}-r_{B}^{2}}{2 \cdot r_{B}^{2}} \cdot \psi^{\prime}$ 


$$
\begin{aligned}
& \left\{\begin{array}{l}
\sin \left(\delta+\psi_{2}\right)=\sin \delta \cdot \cos \psi_{2}+\sin \psi_{2} \cdot \cos \delta= \\
=\frac{d-b \cdot \cos \psi_{2} \cdot\left(1-\psi^{\prime}\right)}{R A D}
\end{array}\right. \\
& \left\{\begin{array}{l}
\cos \left(\delta+\psi_{2}\right)=\cos \delta \cdot \cos \psi_{2}-\sin \delta \cdot \sin \psi_{2}= \\
=\frac{b \cdot \sin \psi_{2} \cdot\left(1-\psi^{\prime}\right)}{R A D}
\end{array}\right. \\
& \left\{\begin{array}{l}
\cos B=\sin \left(\delta+\psi_{2}\right) \cdot \cos \alpha_{B}+ \\
+\sin \alpha_{B} \cdot \cos \left(\delta+\psi_{2}\right)= \\
=\frac{d^{2}+b^{2} \cdot\left(1-\psi^{\prime}\right)-d \cdot b \cdot \cos \psi_{2} \cdot\left(2-\psi^{\prime}\right)}{r_{B} \cdot R A D}
\end{array}\right. \\
& \left\{\begin{array}{l}
\sin B=\sin \left(\delta+\psi_{2}\right) \cdot \sin \alpha_{B}- \\
-\cos \left(\delta+\psi_{2}\right) \cdot \cos \alpha_{B}=\frac{b \cdot \psi^{\prime}}{r_{B}} \cdot \cos \delta
\end{array}\right. \\
& \left\{\begin{array}{l}
\cos \alpha=-\cos \left(\psi_{2}+\delta+\alpha_{A}\right)= \\
=\sin \left(\psi_{2}+\delta\right) \cdot \sin \alpha_{A}-\cos \left(\psi_{2}+\delta\right) \cdot \cos \alpha_{A}
\end{array}\right. \\
& \cos \alpha=\frac{\psi^{\prime} \cdot b}{r_{A}} \cdot \cos \delta \\
& \cos \alpha \cdot \cos \delta=\frac{\psi^{\prime} \cdot b}{r_{A}} \cdot \cos ^{2} \delta \\
& \theta_{A}=\phi+\gamma \\
& \gamma=\alpha_{A}-\alpha_{0} \\
& \dot{\theta}_{A}=\dot{\phi}+\dot{\gamma}=\omega+\dot{\alpha}_{A} \\
& \theta_{A}^{\prime}=1+\alpha_{A}^{\prime}
\end{aligned}
$$$$
r_{A}^{2}=r_{B}^{2}+r_{b}^{2}-2 \cdot r_{b} \cdot r_{B} \cdot \cos B
$$$$
r_{A}=\sqrt{r_{A}^{2}}
$$$$
\cos \mu=\frac{r_{A}^{2}+r_{B}^{2}-r_{b}^{2}}{2 \cdot r_{A} \cdot r_{B}}
$$$$
\sin \mu=\frac{r_{b}}{r_{A}} \cdot \sin B
$$$$
B^{\prime}=\delta^{\prime}+\psi^{\prime}+\alpha_{B}^{\prime}
$$$$
r_{A}^{\prime}=\frac{r_{B} \cdot r_{B}^{\prime}-r_{b} \cdot r_{B}^{\prime} \cdot \cos B+r_{b} \cdot r_{B} \cdot \sin B \cdot B^{\prime}}{r_{A}}
$$$$
\mu^{\prime}=\frac{r_{b}}{r_{A} \cdot \cos \mu} \cdot\left(\cos B \cdot B^{\prime}-\sin B \cdot \frac{r_{A}^{\prime}}{r_{A}}\right)
$$$$
\alpha_{A}=\alpha_{B}+\mu
$$$$
\alpha_{A}^{\prime}=\alpha_{B}^{\prime}+\mu^{\prime}
$$$$
\cos \alpha_{A}=\cos \alpha_{B} \cos \mu-\sin \alpha_{B} \sin \mu
$$$$
\sin \alpha_{A}=\sin \alpha_{B} \cos \mu+\cos \alpha_{B} \sin \mu
$$$$
\alpha=\pi-\alpha_{A}-\psi_{2}-\delta
$$

Relations to Draw (Synthesis) the Cam Profile, to the Module F

Next few cinematic parameters are determined by which cam profile can be traced directly (to the rotating cam and rocker follower with roll); relations 3.57-3.64:

$$
\begin{aligned}
& \cos \alpha_{0}=\frac{\left(r_{0}+r_{b}\right)^{2}+d^{2}-b^{2}}{2 \cdot\left(r_{0}+r_{b}\right) \cdot d} \\
& \sin \alpha_{0}=\frac{b \cdot \sin \psi_{0}}{r_{0}+r_{b}} \\
& \cos \gamma=\cos \alpha_{A} \cdot \cos \alpha_{0}+\sin \alpha_{A} \cdot \sin \alpha_{0} \\
& \sin \gamma=\sin \alpha_{A} \cdot \cos \alpha_{0}-\sin \alpha_{0} \cdot \cos \alpha_{A} \\
& \cos \theta_{A}=\cos \phi \cdot \cos \gamma-\sin \phi \cdot \sin \gamma \\
& \sin \theta_{A}=\sin \phi \cdot \cos \gamma+\sin \gamma \cdot \cos \phi \\
& x_{A}=r_{A} \cdot \cos \theta_{A} \\
& y_{A}=r_{A} \cdot \sin \theta_{A}
\end{aligned}
$$

\section{The Cam Profile Module F of Law C4P}

Below (Fig. 13) one can see the cam profile for an original law called by author $\mathrm{C} 4 \mathrm{P}$, which support a rotation speed of the drive shaft of 40000 [rpm], compared with the classical distribution who support a maximum drive shaft rotation speed of 5000-6000 [rpm]. 


\section{The Dynamic Coefficient D}

The dynamic coefficient is expressed with relation (3.65), where $\cos ^{2} \delta$ has the expression (3.66) and $\theta_{A}^{\prime}$ is given by the expression (3.67):

$D=\theta_{A}^{\prime} \cdot \cos ^{2} \delta$

$\cos ^{2} \delta=$

$=\frac{d^{2} \cdot \sin ^{2} \psi_{2}}{d^{2}+b^{2} \cdot\left(1-\psi^{\prime}\right)^{2}-2 \cdot b \cdot d \cdot\left(1-\psi^{\prime}\right) \cdot \cos \psi_{2}}$

$\theta_{A}^{\prime}=1+\frac{d^{2}-b^{2}-r_{B}^{2}}{2 \cdot r_{B}^{2}} \cdot \psi^{\prime}+$

$+\frac{r_{b}}{r_{A} \cdot \cos \mu} \cdot\left(\cos B \cdot B^{\prime}-\sin B \cdot \frac{r_{A}^{\prime}}{r_{A}}\right)$

\section{Synthesis of the Distribution Mechanism Module H}

In the Fig. 14 one can see the module $\mathrm{H}$, with rotation cam and rotated plane tappet, in initial position and in some one position.

For general use kinematic relations are inserted 4.1-4.4:

$$
\begin{aligned}
& A H= \\
& =\left[\sqrt{d^{2}-\left(r_{0}-b\right)^{2}} \cdot \cos \psi-\left(r_{0}-b\right) \cdot \sin \psi\right] \cdot \frac{\psi^{\prime}}{1-\psi^{\prime}} \\
& O H=b+\left(r_{0}-b\right) \cdot \cos \psi+\sqrt{d^{2}-\left(r_{0}-b\right)^{2}} \cdot \sin \psi
\end{aligned}
$$

$$
r^{2}=A H^{2}+O H^{2}
$$

$$
\left\{\begin{array}{l}
\sin \tau=\frac{A H}{r} ; \\
\sin ^{2} \tau=\frac{A H^{2}}{r^{2}}=\frac{A H^{2}}{A H^{2}+O H^{2}}
\end{array}\right.
$$

In the Fig. 15 one can see and the velocities and the forces of this type of distribution mechanism.

In the Fig. 16 it can see a cam profile at the module $\mathrm{H}$ (with rotation cam and rotating plate follower), for a law sine.

The phase angle is $\varphi_{u}=\varphi_{c}=80$ [deg]; core radius has value $\mathrm{r}_{0}=13[\mathrm{~mm}]$.

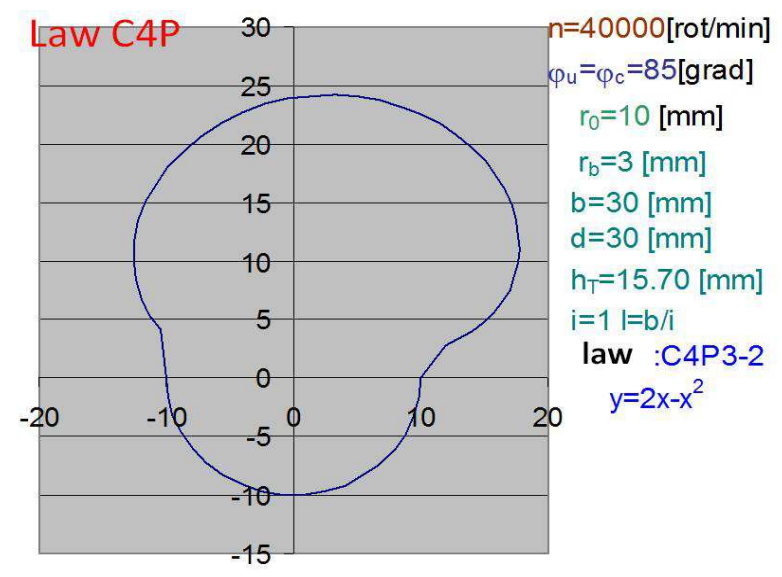

Fig. 13. Synthesis of the cam profile for module $\mathrm{F}$ with the law C4P

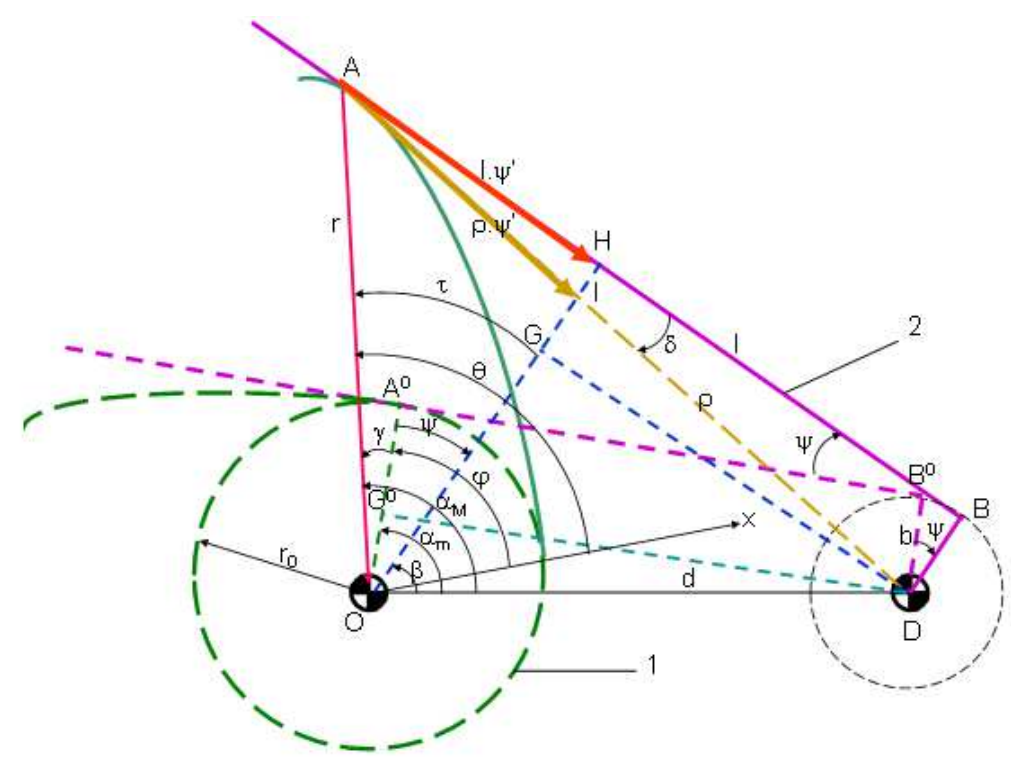

Fig. 14. The distribution mechanism for module $\mathrm{H}$ 


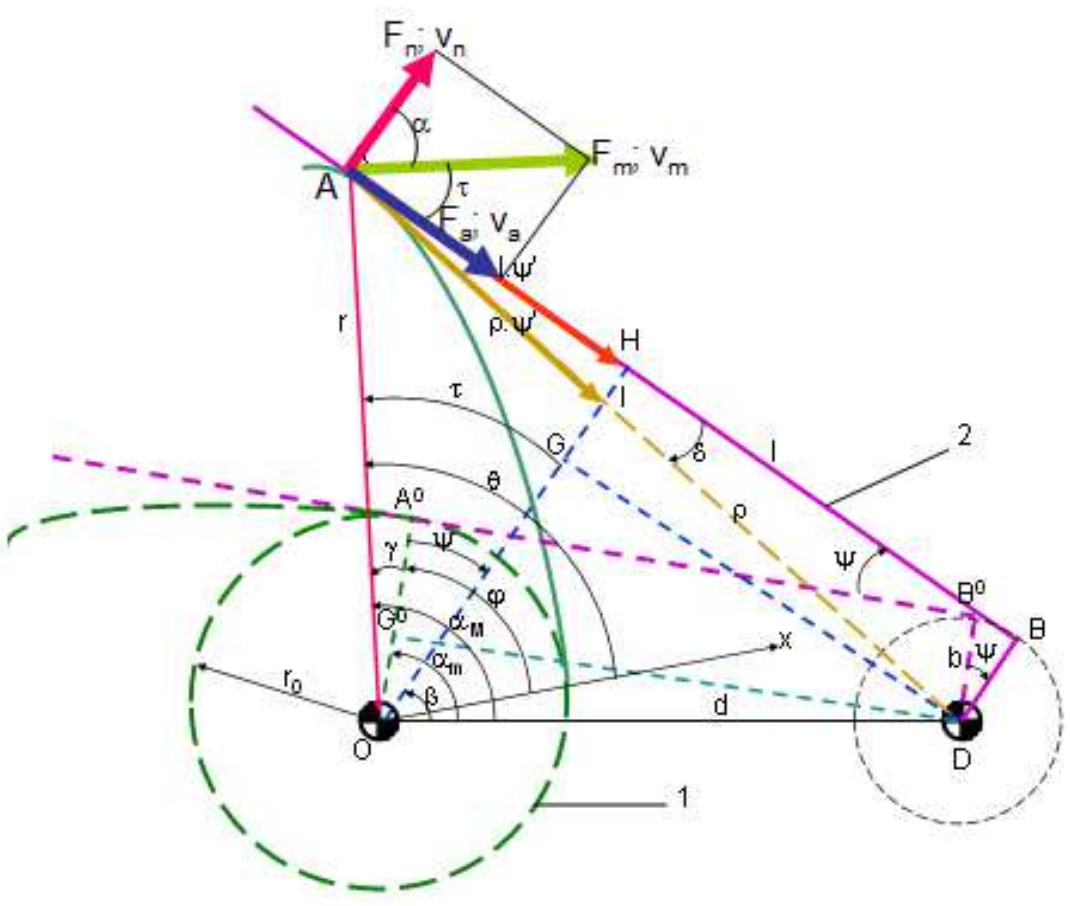

Fig. 15. The distribution mechanism module $\mathrm{H}$; forces and velocities

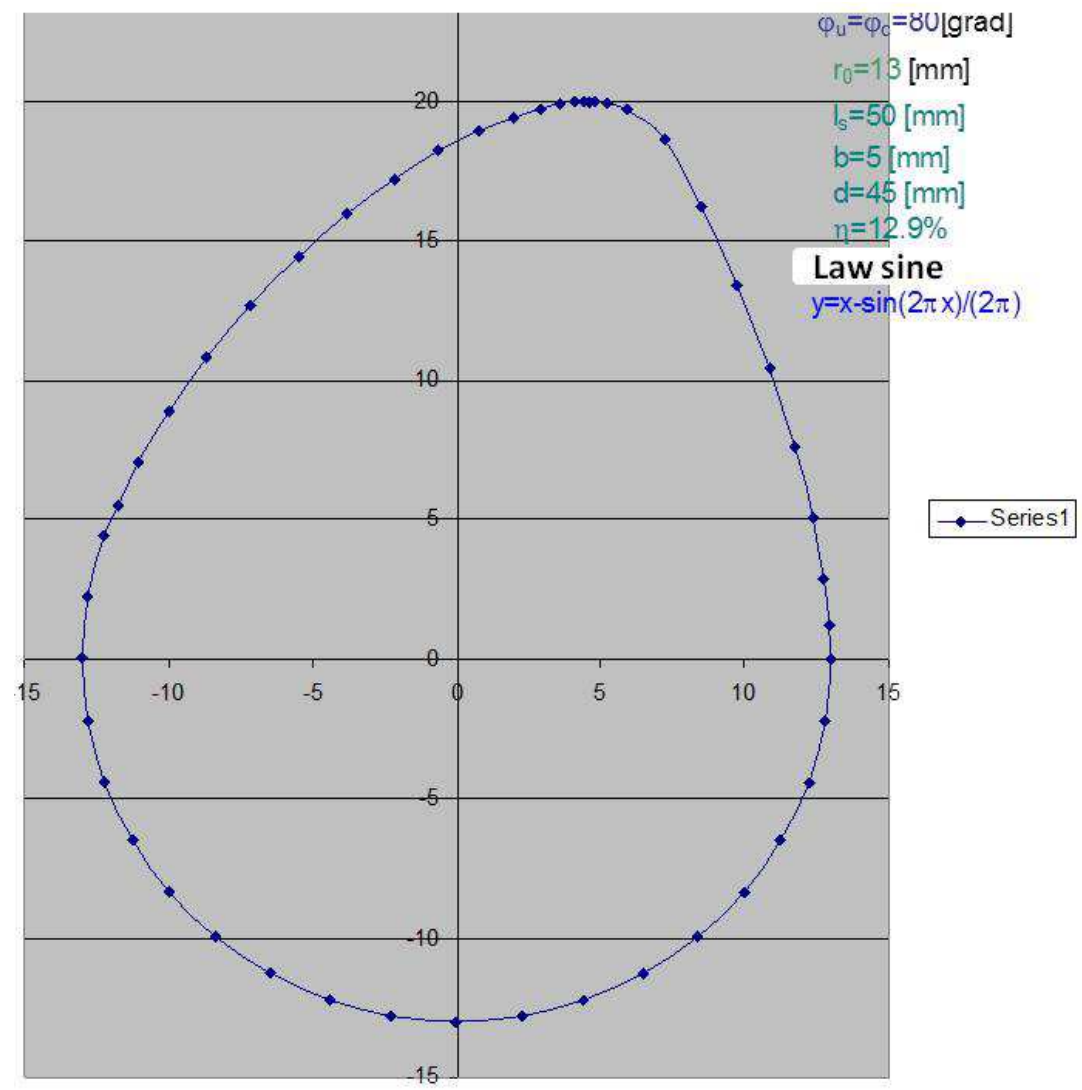

Fig. 16. A cam profile at the module $H$, for a law sine: $\varphi_{u}=\varphi_{c}=80[\mathrm{deg}] ; r_{0}=13[\mathrm{~mm}] ; \eta=12.9 \%$ 


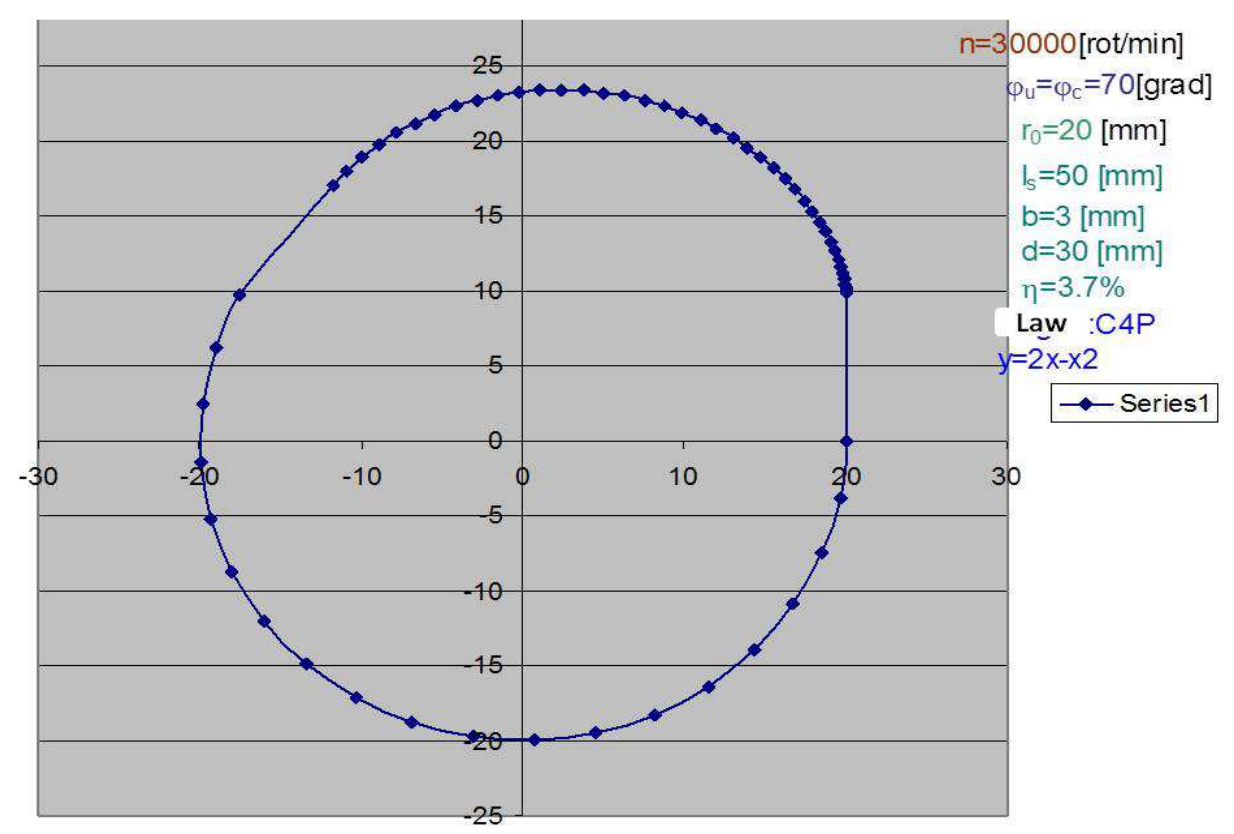

Fig. 17. A cam profile at the module $H$, for a law C4P: $\varphi_{u}=\varphi c=70[\mathrm{deg}] ; \mathrm{r}_{0}=20[\mathrm{~mm}] ; \eta=4 \%$

In the Fig. 17 it can see a cam profile at the module $\mathrm{H}$ (with rotation cam and rotating plate follower), for a law C4P. The phase angle is $\varphi_{u}=\varphi_{c}=70$ [deg]; core radius has value $r_{0}=20[\mathrm{~mm}]$. This profile support a drive shaft rotation speed of 30000 [rpm].

\section{Discussion}

The synthesis of these types of distribution mechanisms can be made shortly, by the Cartesian coordinates, but to determine these coordinates we need and some trigonometric parameters.

This synthesis method, which is based on trigonometric parameters (in a great proportion), can be named a trigonometric synthesis method. At the heat engine with internal combustion a great loss of power is realized and by the distribution mechanism, reason for that we must try to improve the functionality of this mechanism.

Based on presented relationships one can still set up both analysis and synthesis of dynamic mechanism.

Relations presented in short in this study, therefore they have a basic character because they can generate then and dynamic relations.

As long as we produce electricity and heat by burning fossil fuels is pointless to try to replace all thermal engines with electric motors, as loss of energy and pollution will be even larger.

However, it is well to continuously improve the thermal engines, to reduce thus fuel consumption.
At the heat engine with internal combustion a great loss of power is realized and by the distribution mechanism, reason for that we must try to improve the functionality of this mechanism.

\section{Benefits}

The main advantage is that the $\mathrm{B}, \mathrm{F}$ and $\mathrm{H}$ modules supports a much higher speed compared to classic module C (An engine with high rotation speed can be more compact, more powerful and more economical and without nuisance).

To the modules $\mathrm{B}, \mathrm{F}$ and $\mathrm{H}$ we can increase and the yield of the mechanism.

\section{Conclusion}

The paper presents shortly some original trigonometric methods to make the synthesis of a mechanism with rotary cam and translated or rotated tappet plate or with roll, used with priority at the distribution mechanisms from the heat engines with internal combustion. These types of distribution can improve the changes of gases and may decrease significantly the level of vibration, noises and emissions.

\section{Ethics}

This article is original and contains unpublished material. The corresponding author approved the manuscript and confirms that no ethical issues involved. 


\section{References}

Amoresano, A., V. Avagliano, V. Niola and G. Quaremba, 2013. The assessment of the in-cylinder Pressure by means of the morpho-dynamical vibration analysis-methodology and application. IREME J., 7: 999-1006.

Anderson, R.B., 1984. The Fischer-Tropsch Synthesis. 1 st Edn., Academic Press.

Angelas, J. and C. Lopez-Cajun, 1988. Optimal synthesis of cam mechanisms with oscillating flat-face followers. Mechanism Machine Theory, 23: 1-6. DOI: 10.1016/0094-114X(88)90002-X

Antonescu, P., F. Petrescu and O. Antonescu, 2000. Contributions to the synthesis of the rotary disccam profile. Proceedings of the 8th International Conference on the Theory of Machines and Mechanisms, (TMM' 00), Liberec, Czech Republic, pp: 51-56.

Antonescu, P., M. Oprean and F.I. Petrescu, 1987. Analiza dinamică a mecanismelor de distribuție cu came. Proceedings al 7-lea Simpozion National de Roboti Industriali, (NRI' 87), Bucureşti, pp: 126-133.

Barzegari, A., 2011. A new algorithm based on particle swarm optimization for solving power economic dispatch considering valve-point effects and emission constraints. I.RE.MO.S. J., 4: 1303-1311.

Bishop, J.L.H., 1950. An analytical approach to automobile. valve gear design. Proc. Instit. Mechan. Eng., 4: 150-160.

DOI: 10.1243/PIME_AUTO_1950_000_018_02

Choi, J.K. and S.C. Kim, 1994. An experimental study on the frictional characteristics in the valve train system. Proceedings of the 1st Congress, Oct. 17-21, Beijing, pp: 374-380.

De Falco, D., G. Di Massa, S. Pagano and S. Strano, 2013a. Motorcycle handlebar dynamic response: Theoretical and experimental investigation. IREME J., 7: 795-801.

De Falco, D., G. Di Massa and S. Pagano, 2013b. A full scale motorcycle dynamic rig. IREME J., 7: 519-526.

Ganapathi, P. and Y. Robinson, 2013. Experimental investigation of performance and emission characteristics of DI diesel engine fueled with polymer waste dissolved in biodiesel-blended diesel fuel. IREME J., 7: 919-924.

DOI: 10.1016/j.energy.2012.07.049

Giordana, F., V. Rognoni and G. Ruggieri, 1979. On the influence of measurement errors in the Kinematic analysis of cams. Mechanism Machine Theory, 14: 327-340. DOI: 10.1016/0094-114X(79)90019-3

Hain, K., 1971. Optimization of a cam mechanism-to give good transmissibility, maximal output angle of swing and minimal acceleration. J. Mechanisms, 6: 419-434. DOI: 10.1016/0022-2569(71)90044-9
Heywood, J.B., 1988. Internal Combustion Engine Fundamentals. 1st Edn., McGraw-Hill, New York, ISBN-10: 007028637X, pp: 930.

Hrones, J.A., 1948. An analysis of dynamic forces in a cam-driver system. Trans. ASME, 70: 473-482.

Karikalan, L., M. Chandrasekaran and K. Sudhagar, 2013. Comparative studies on vegetable oil usage in C.I engines as an alternative to diesel fuel. IREME J., 7: 705-715.

Leidel, J.A., 1997. An optimized low heat rejection engine for automotive use-an inceptive study. SAE International.

Mahalingam, S. and B.R. Ramesh Bapu, 2013. Experimental and emission analysis of rubber seed oil and jatropha oil blends with diesel in compression ignition engine. IREME J., 7: 955-959.

Naima, K. and A. Liazid, 2013. Numerical investigation on combustion behaviors of direct-injection spark ignition engine fueled with CNG-hydrogen blends. IREME J., 7: 652-663.

Narasiman, V., S. Jeyakumar and M. Mani, 2013. Optimizing the compression ratio of C.I engine fuelled in sardine oil ethyl ester. IREME J., 7: 463-467.

Petrescu, F. and R. Petrescu, 1995. Contributii la sinteza mecanismelor de distributie ale motoarelor cu ardere internã.

Petrescu, F.I. and R.V. Petrescu, 2005a. Contributions at the dynamics of cams. Proceedings of the 9th IFToMM International Symposium on Theory of Machines and Mechanisms, (TMM' 05), Bucharest, Romania, pp: 123-128.

Petrescu, F.I. and R.V. Petrescu, 2005b. Determining the dynamic efficiency of cams. Proceedings of the 9th IFToMM International Symposium on Theory of Machines and Mechanisms, (TMM' 05), Bucharest, Romania, pp: 129-134.

Petrescu, F.I., R.V. Petrescu and N. Popescu, 2005. The efficiency of cams. Proceedings of the 2nd International Conference "Mechanics and Machine Elements", Nov. 4-6, Technical University of Sofia, Sofia, Bulgaria, pp: 237-243.

Petrescu, F.I., 2008. Cams Dynamic Efficiency Determination. In: New Trends in Mechanisms, Academica-Greifswald, ISBN-13: 978-3-940237-10-1, pp: 49-56.

Petrescu, F.I. and R.V. Petrescu, 2014. Cam gears dynamics in the classic distribution. Independent $\mathrm{J}$. Manage. Product., 5: 166-185.

Petrescu, F.I. and R.V. Petrescu, 2013a. An algorithm for setting the dynamic parameters of the classic distribution mechanism. IREMOS J., 6: 1637-1641.

Petrescu, F.I. and R.V. Petrescu, 2013b. Dynamic synthesis of the rotary cam and translated tappet with roll. IREMOS J., 6: 600-607. 
Petrescu, F.I. and R.V. Petrescu, 2011. Dinamica mecanismelor de distributie. Create Space Publisher, USA.

Petrescu, F.I., 2012a. Bazele analizei și optimizării sistemelor cu memorie rigidă-curs și aplicații. Create Space Publisher, USA.

Petrescu, F.I., 2012b. Teoria mecanismelor-Curs si aplicatii (editia a doua). Create Space Publisher, USA.

Petrescu, F.I. and R.V. Petrescu, 2013c. Forces and efficiency of cams. IREME, 7: 507-511.

Petrescu, F.I. and R.V. Petrescu, 2013d. Cams with high efficiency. IREME, 7: 599-606.

Rahmani, L., B. Draoui, M. Bouanini and E. Benachour, 2013. CFD study on heat transfer to bingham fluid during with gate impeller. IREME, 7: 1074-1079.

Ravi, S. and R. Subramanian, 2013. Diesel fuel additives: An overview. IREME, 7: 698-704.

Ronney, P.D., M. Shoda, S.T. Waida and E.J. Durbin, 1994. Throttleless premixed-charge engines: Concept and experiment. J. Automobile Eng., 208: 13-24. DOI: 10.1243/PIME PROC $1994208 \quad 153 \quad 02$

Samim, Y. and S.T. Tümer, 1993. Analytical dynamic response of elastic cam-follower systems with distributed parameter Return spring. J. Mech. Design, 115: 612-620. DOI: 10.1115/1.2919234

Sapate, K.D. and A.N. Tikekar, 2013. Engine mapping for improvement in fuel efficiency of two stroke SI engine. IREME, 7: 392-394.
Sethusundaram, P.P., K.P. Arulshri and K. Mylsamy, 2013. Biodiesel blend, fuel properties and its emission characteristics sterculia oil in diesel engine. IREME, 7: 925-929.

Shriram, R., 2012. Design and development of camless valve train for I.C. engines. IREME J., 6: 1044-1049.

Taraza, D., 2002. Accuracy limits of IMEP determination from crankshaft speed measurements. SAE Trans. J. Engines, 111: 689-697.

Wang, W., 2011. Creation design of cam mechanism based on reverse engineering. Adv. Mater. Res. J., 230-232: 453-456.

DOI: 10.4028/www.scientific.net/AMR.230-232.453

Xianying, F., 2011. Meshing efficiency of globoidal indexing cam mechanism with steel ball. Adv. Mater. Res. J., 413: 414-419.

DOI: $10.4028 /$ www.scientific.net/AMR.413.414

Zahari, I., M.A. Abras, N.I. Mat Arishad, S.F. Zainal and M.F. Muhamad, 2013. Experimental study to identify common engine part load conditions between Malaysian city driving and NEDC test. IREME, 7: 1152-1158.

Zhao, H.D., C. Huang, M. Chen, J. Li and G. Hun, 2012. Research on dynamic behavior of disc indexing cam mechanism based on virtual prototype technology. Key Eng. Mater. J., 499: 277-282.

DOI: $10.4028 /$ www.scientific.net/KEM.499.277 